\title{
ATTITUDES OF MALE AND FEMALE STUDENTS OF SECOND STUDIOUS LEVEL IN FACULTY OF AGRICULTURE OF CAIRO UNIVERSITY TOWARDS AGRICULTURAL EXTENSION SPECIALIZATION
}

Sahar A. Hikel

Faculty of Agriculture- Cairo University

إتجاهات طلبة وطالبات المستوى الدراسى الثانى بكلية الزراعة جامعة القاهرة نحو تخصص الإرشاد الزراعى

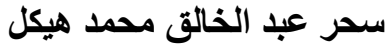
كلية الزراعة - جامعة القاهرة

\begin{abstract}
الملخص

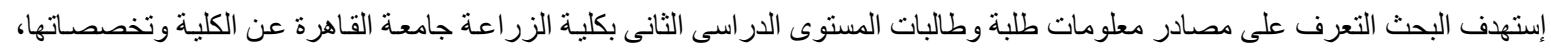

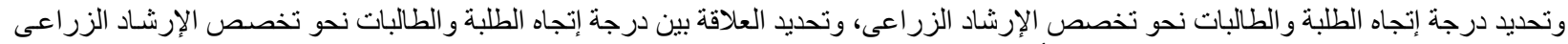

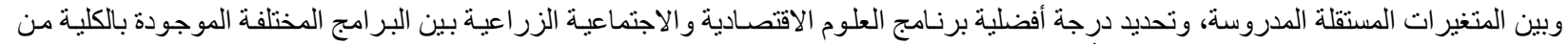

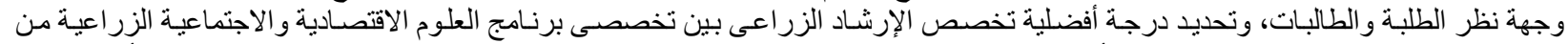

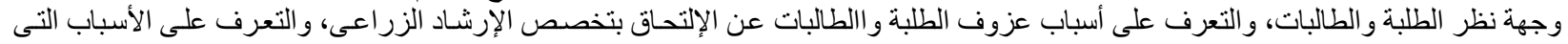

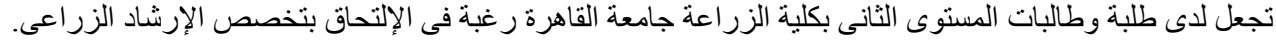

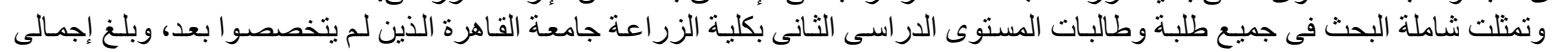

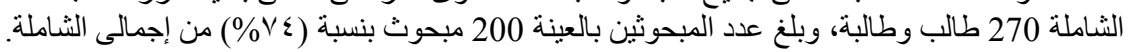

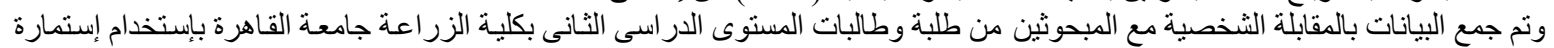

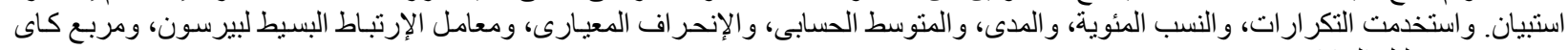
فى عرض وض وتحليل البيانات. وجاءت أهم نتائج البحث كالتالتى الباتى

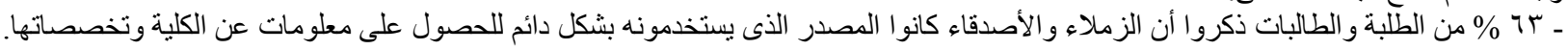

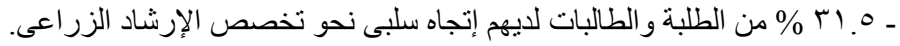

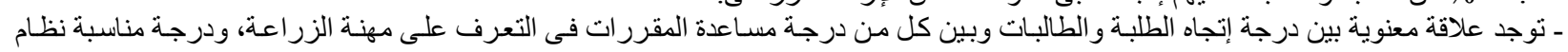

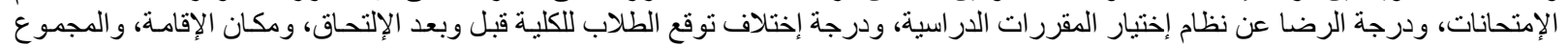
في الثنانوية العامة.

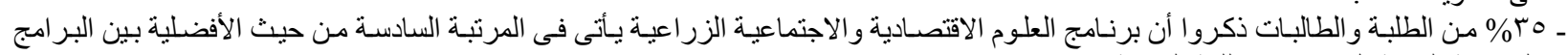
الدر اسية السبعة التى تدرس الطبات باللغة العربية.

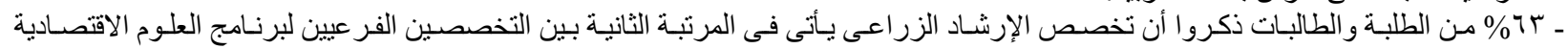
و الاجتماعية الزر اعية. ـ ـ.00\% من الطلبة و الطالبات ذكروا أن قلة فرص العمل بعد التخرج من تخصص الإرشـاد الزر اعى كان أهم أسباب العزوف عن الإلتحاق بهذا
\end{abstract}

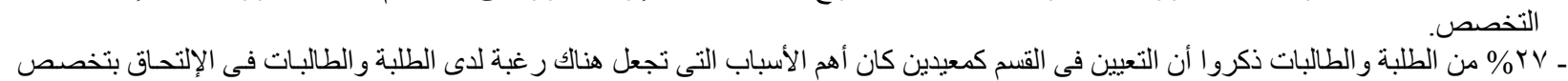
الإرشاد الزر اعى.

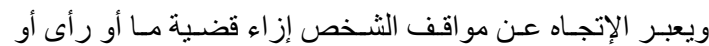

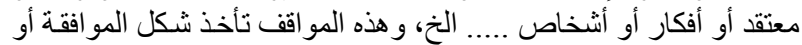

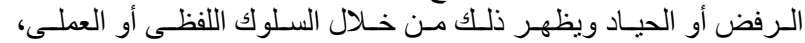

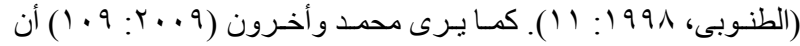

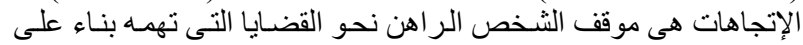

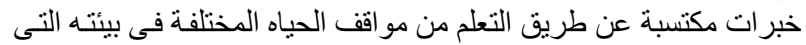

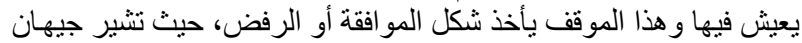

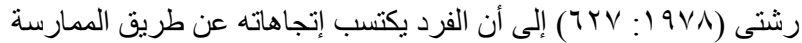

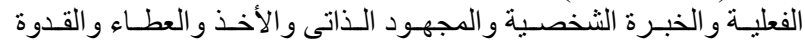

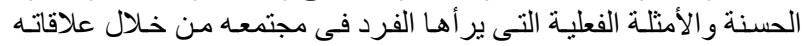
بالأفر اد، و والجماعات الرسمية أو غير الرئة الرسمية.

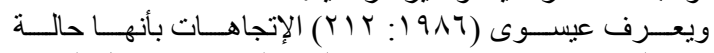

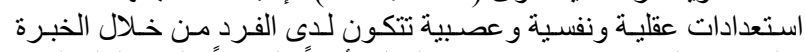

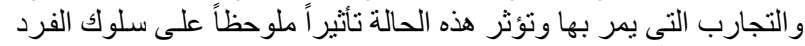

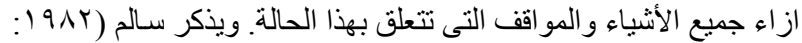

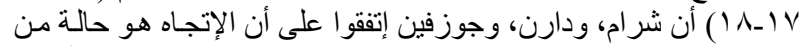

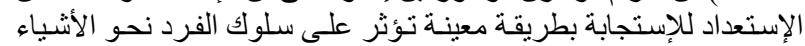

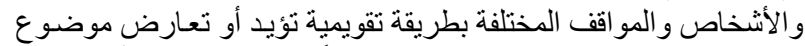

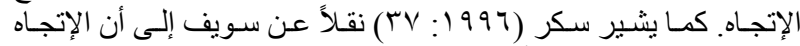

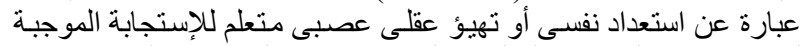

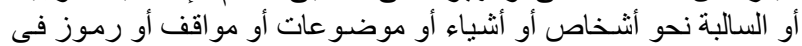
البيئة التى تثير الإستجابة.

\section{المقدمة والمشكلة}

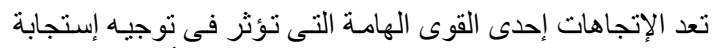

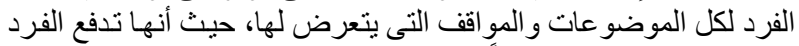

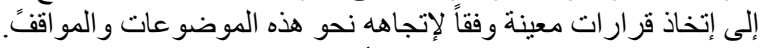

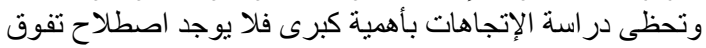

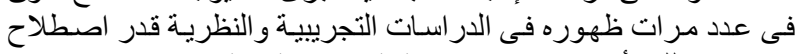

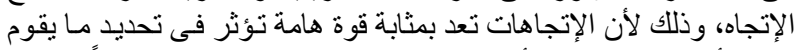

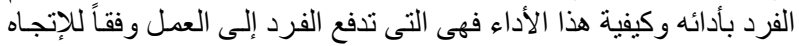

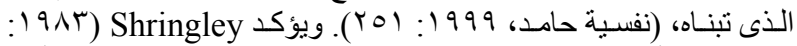

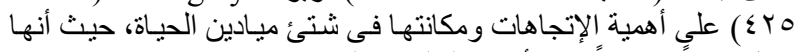

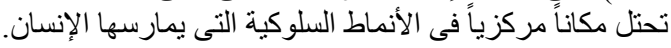

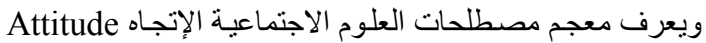

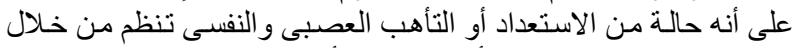

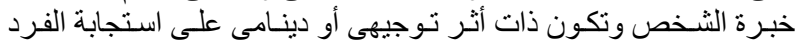

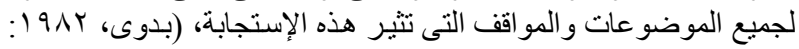

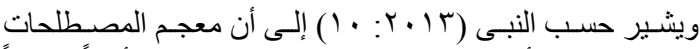
(r.

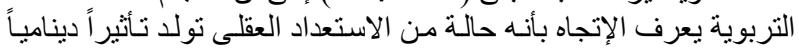

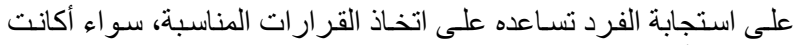

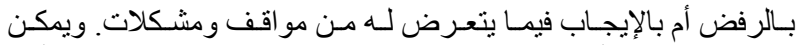

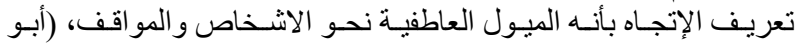

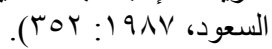


سرية، و إتجاهات قوية أو ضعيفة، و إتجاهـات موجبـة أو سـالبة، و إتجاهات

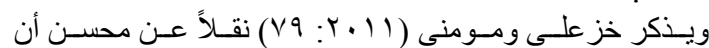
عامة أو خاصة وإنجات

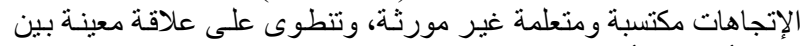

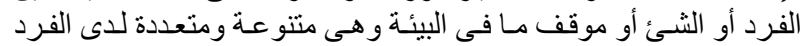

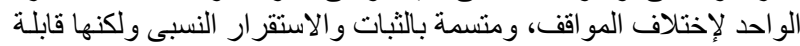

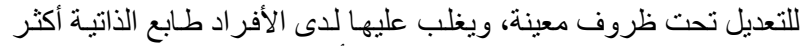

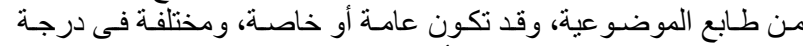

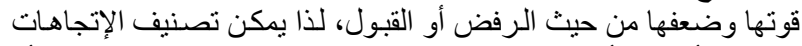

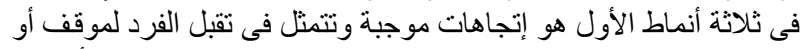

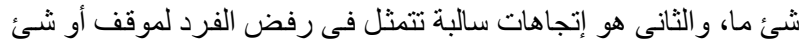

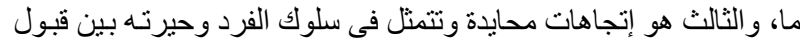
موقف أو شئ ما أو رفضده.

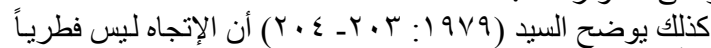

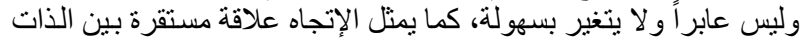

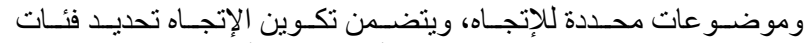

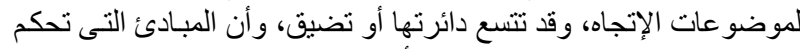

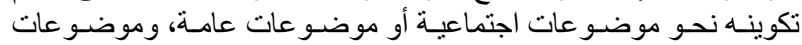

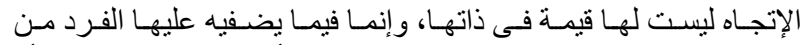

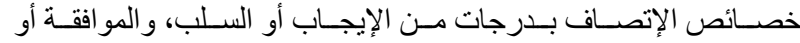

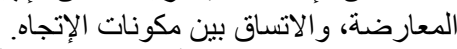

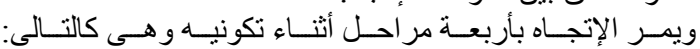

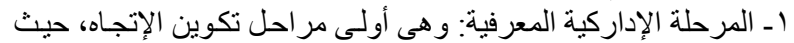

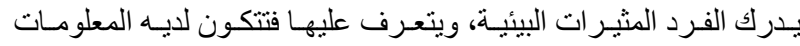

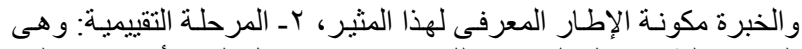

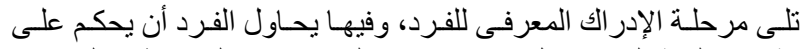

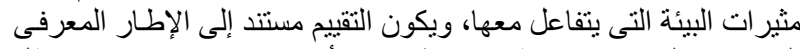

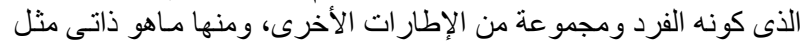

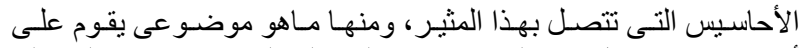

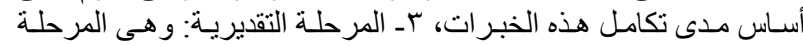

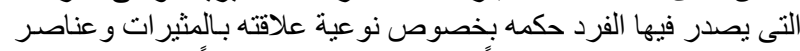

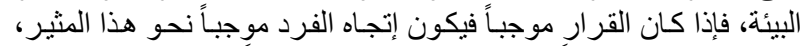

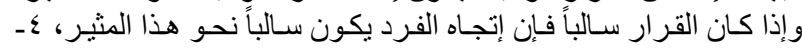

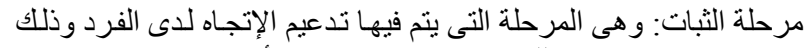

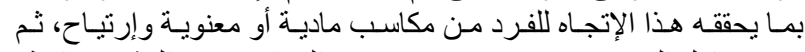

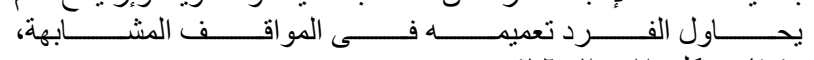

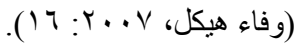

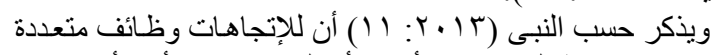

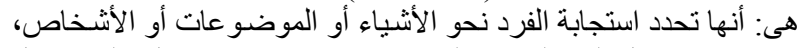

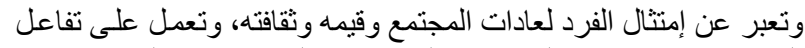

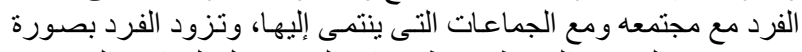

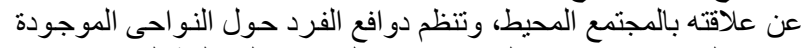

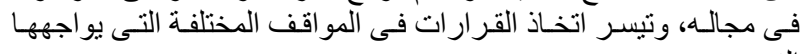

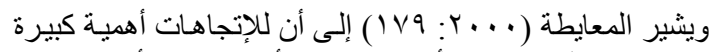

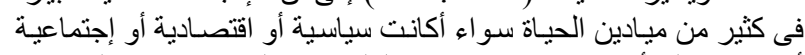

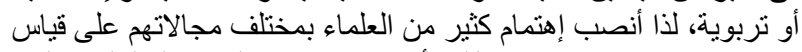

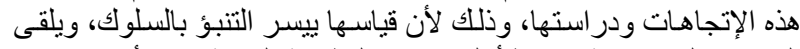

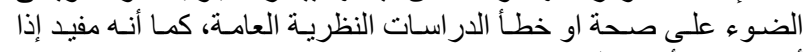

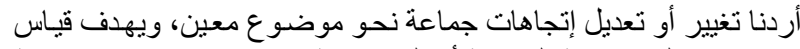

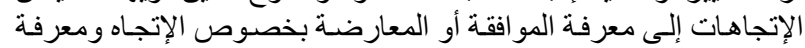

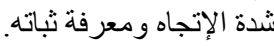

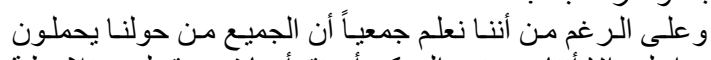

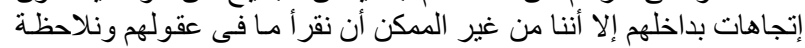

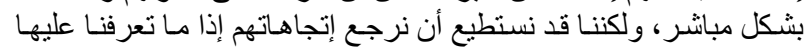

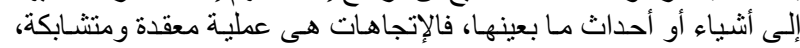

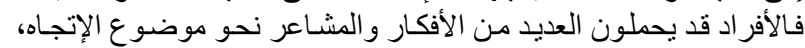

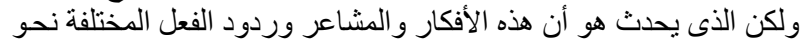

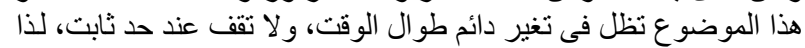

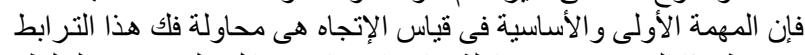

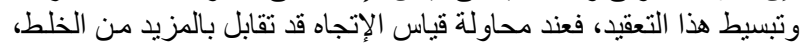

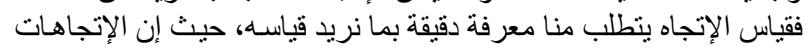

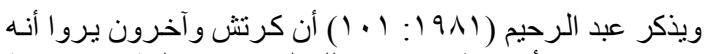

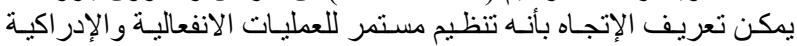

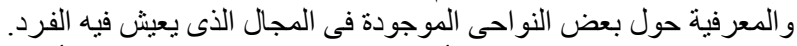

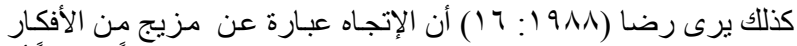

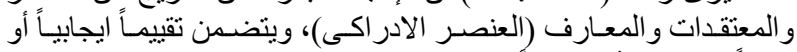

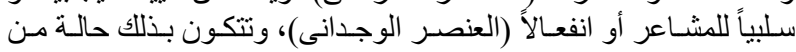

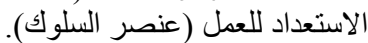

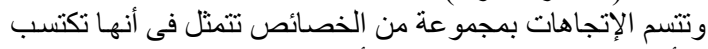

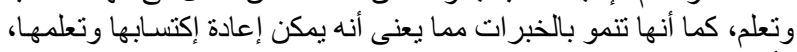

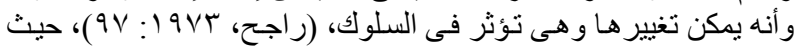

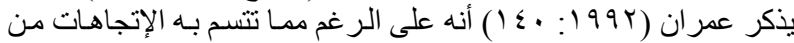

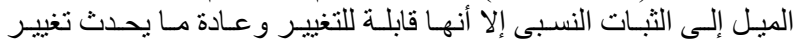

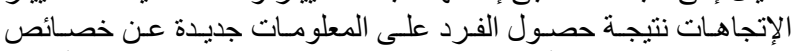

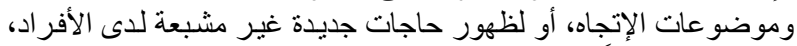

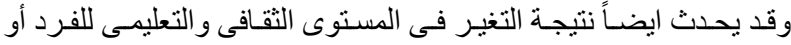

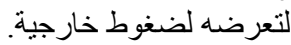

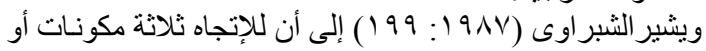

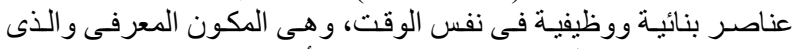

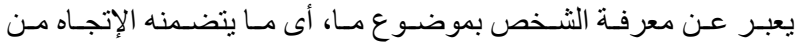

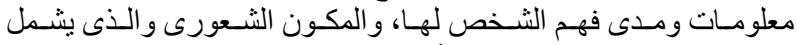

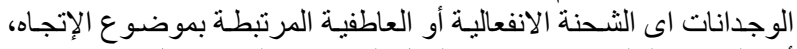

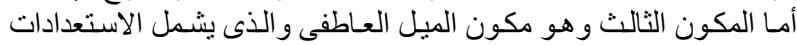

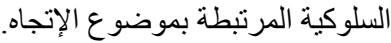

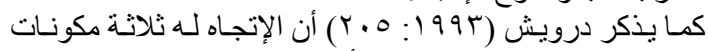

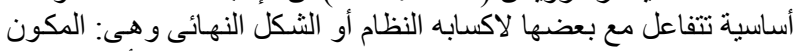

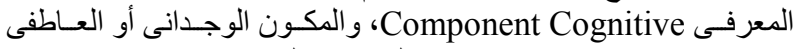

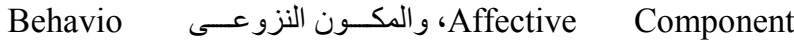
و Component

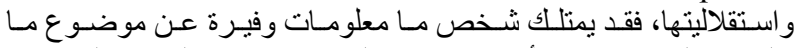

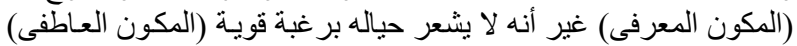

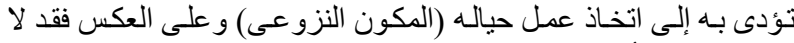

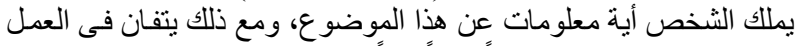

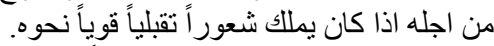

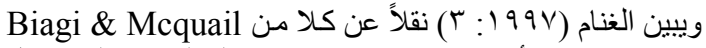

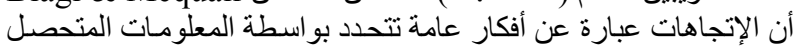

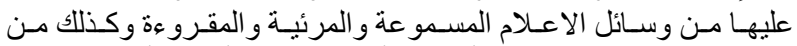

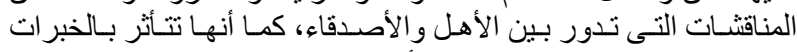

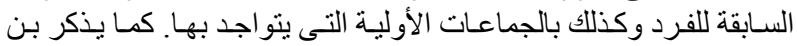

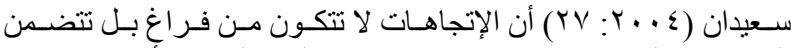

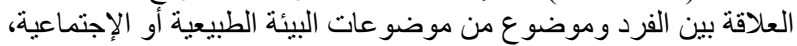

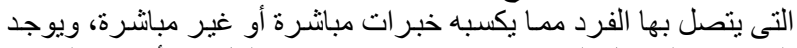

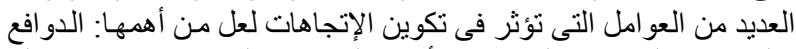

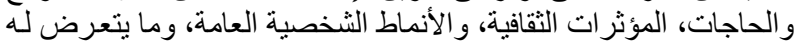

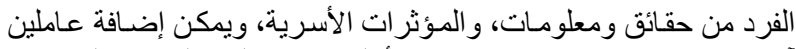

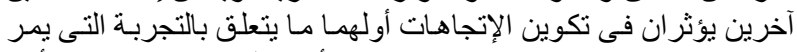

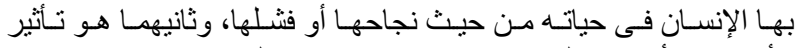

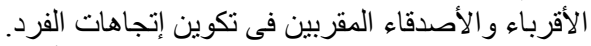

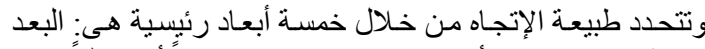

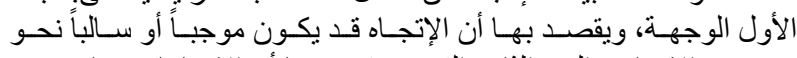

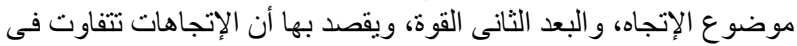

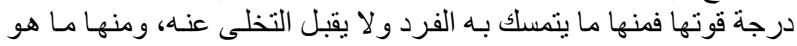

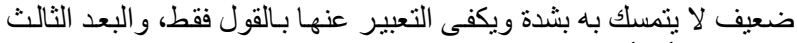

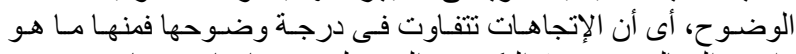

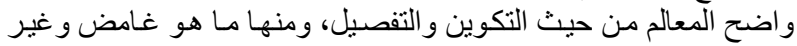

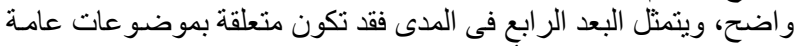

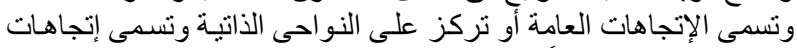

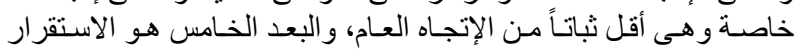

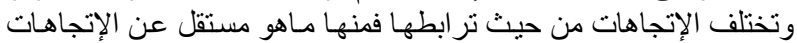

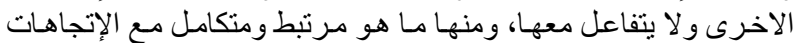

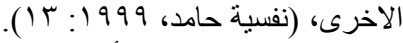

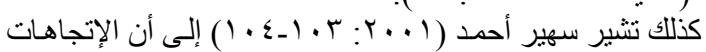

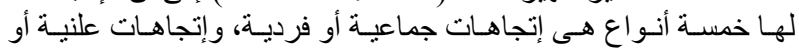




\section{J. Agric. Econom. and Social Sci., Mansoura Univ., Vol.7 (3), March ,2016}

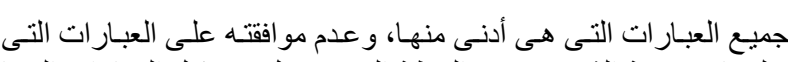

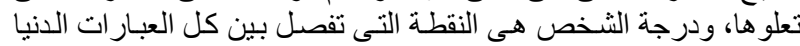

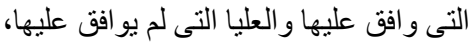

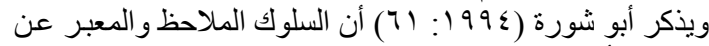

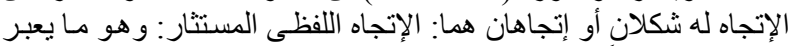

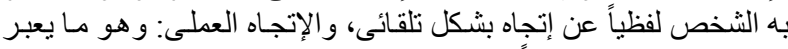

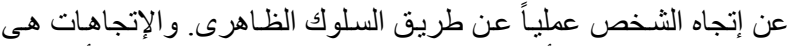

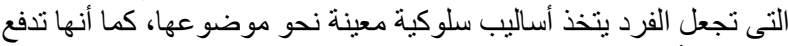

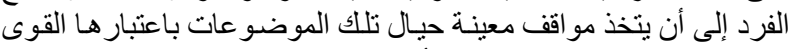

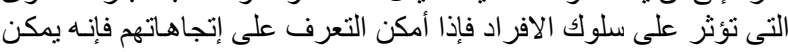

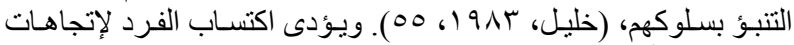

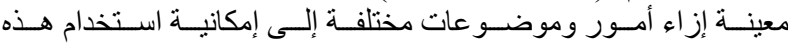

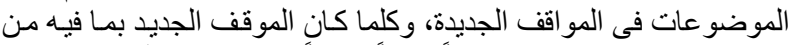

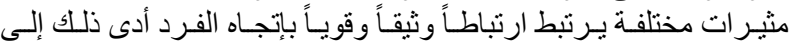

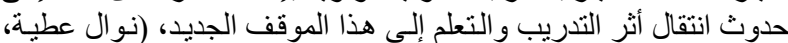

(99:199.

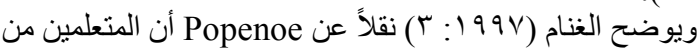

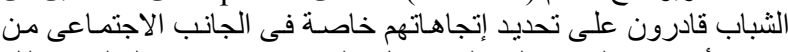

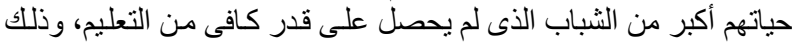

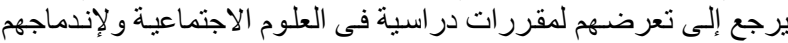
فى الحياة السياسية و الثقافية بالمجتمع.

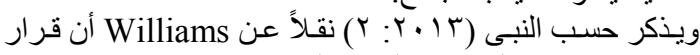

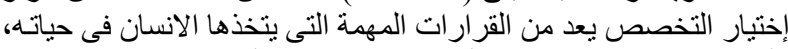

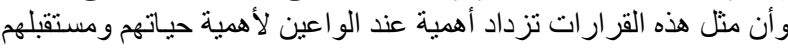

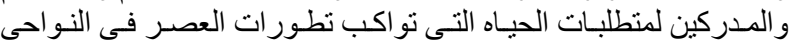

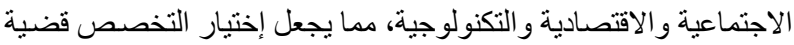

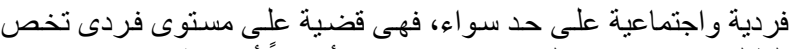

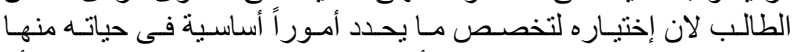

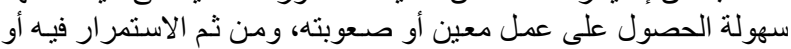

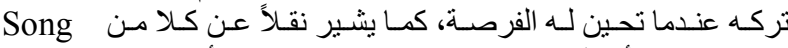
\&Jennifer

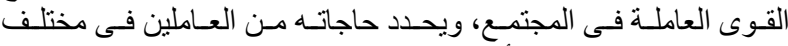

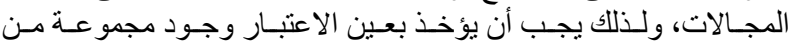

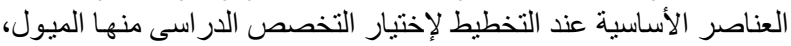

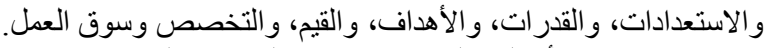

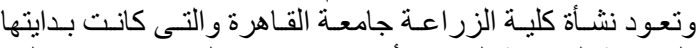

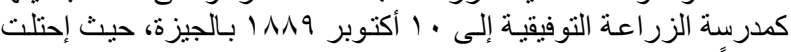

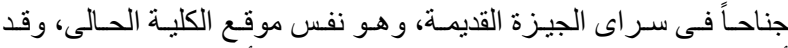

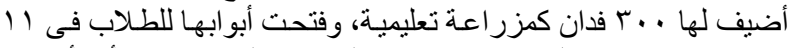

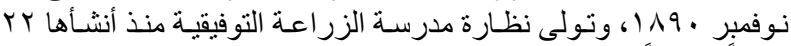

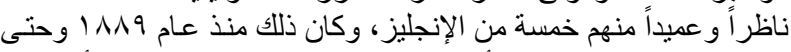

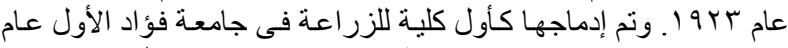

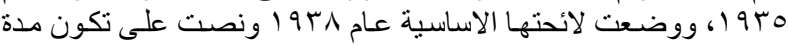

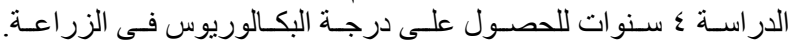

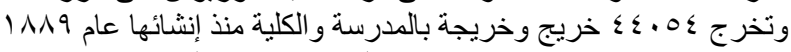

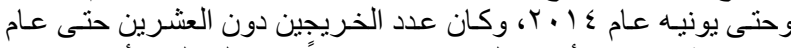

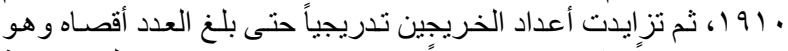

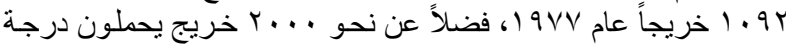

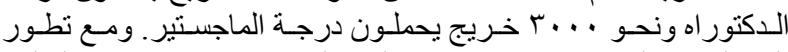

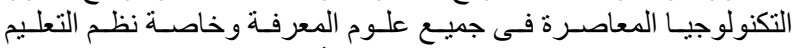

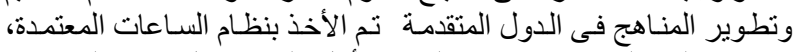

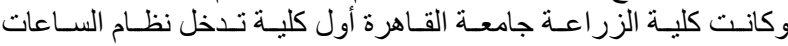

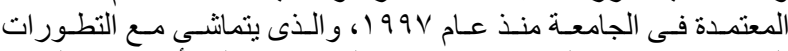

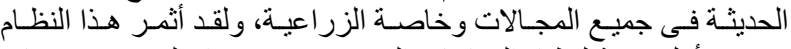

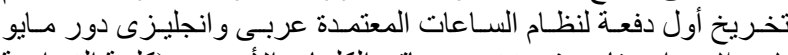

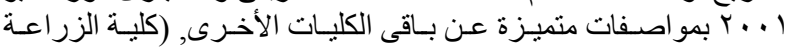

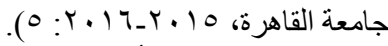

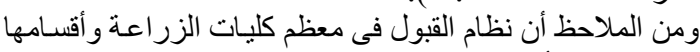

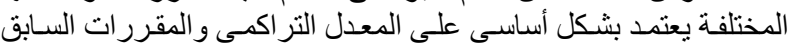

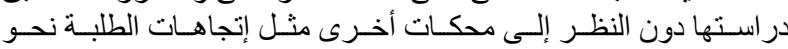

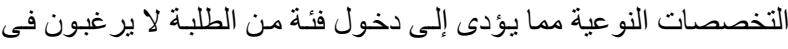

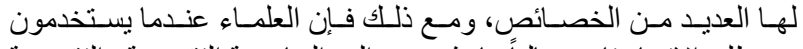

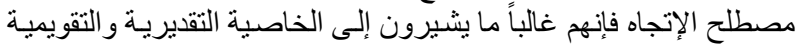

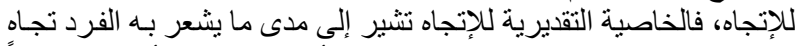

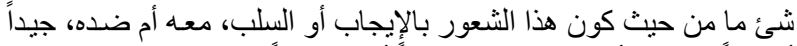

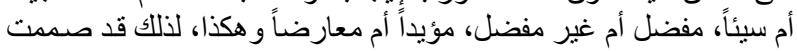

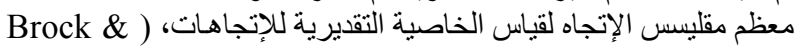
(r. - - Treen ويذكركلا مـن Bohner \& Wanke

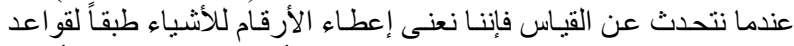

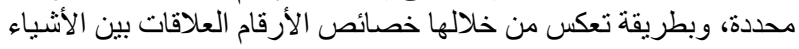

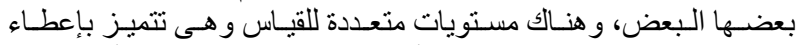

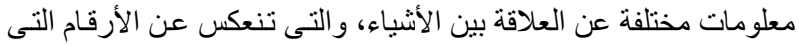

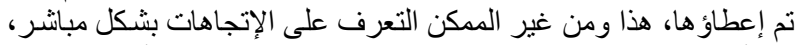

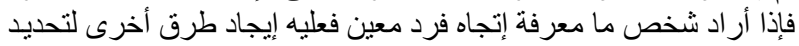

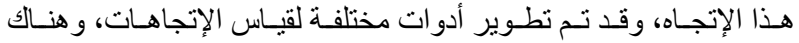

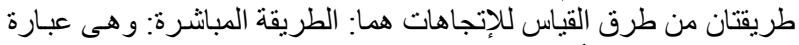

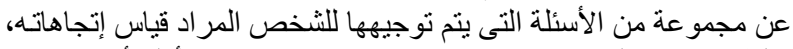

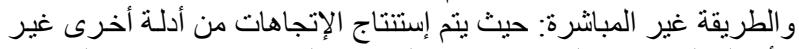

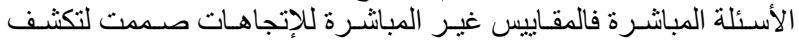

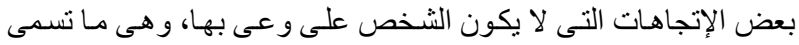
بالإتجاهات الضمنية.

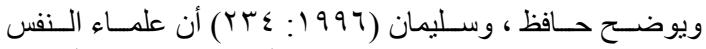

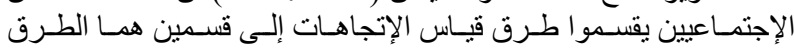

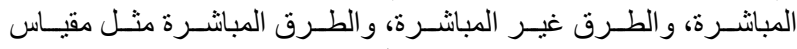

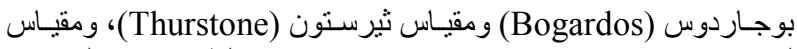

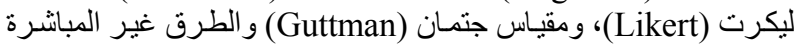
مثل الإختبار ات الإسقاطية.

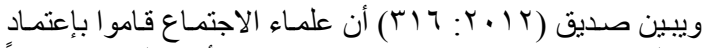

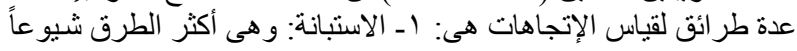

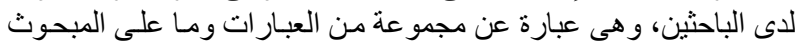

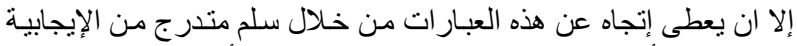

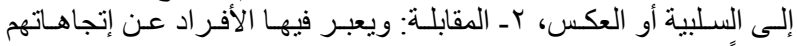

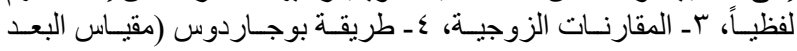

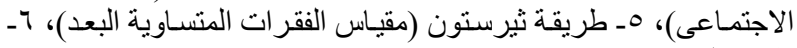
طريقة ليكرت، V V- طريقة جتمان.

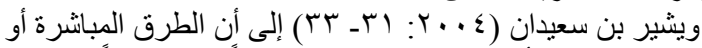

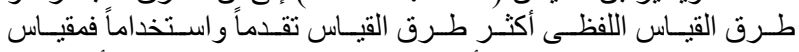

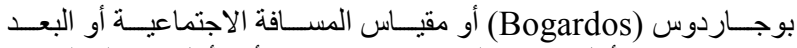

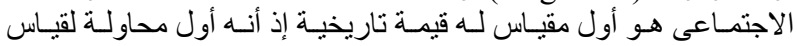

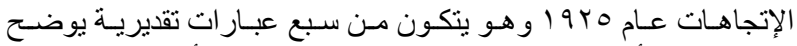

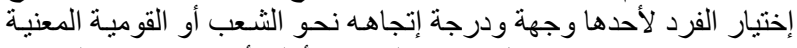

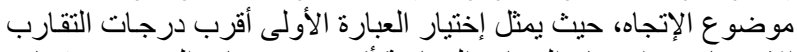

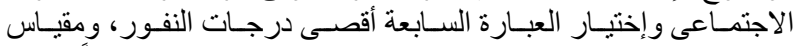

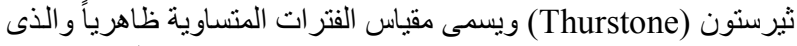

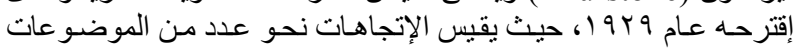

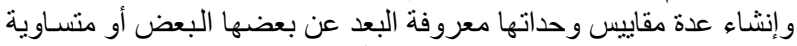

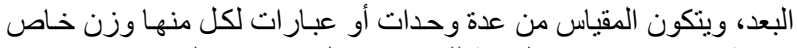

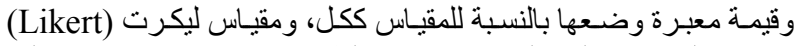

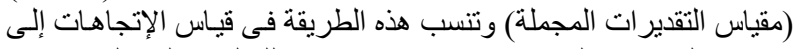

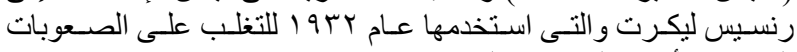
المرتبطة بأحكام المحكمين التى حدثت في مقياس ثيرستون، حيث بثن يتكون

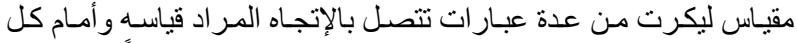

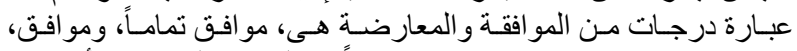

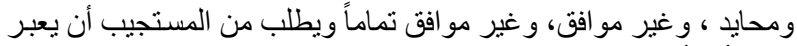

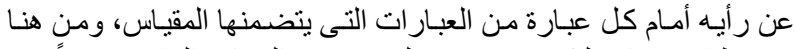

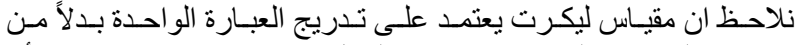

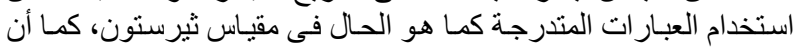

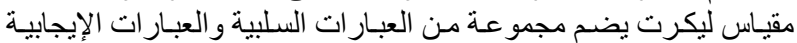

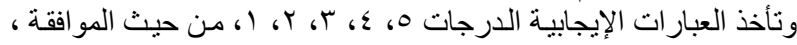

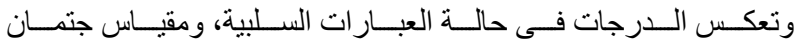

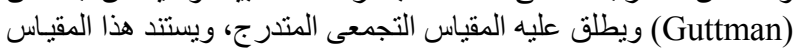

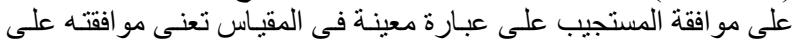




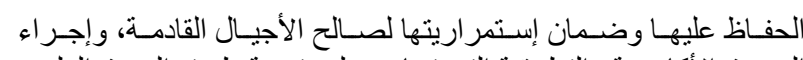

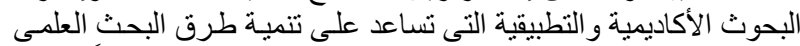

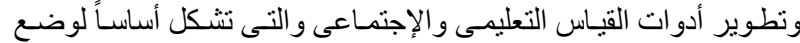

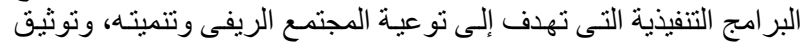

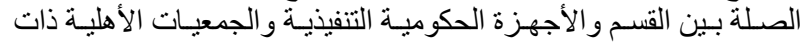

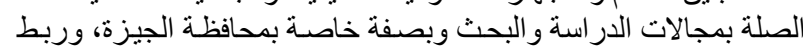

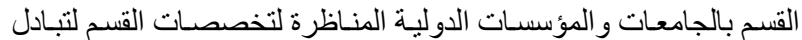
الخبرات وتطوير قدر ات أعضـاء هيئة التدريس و الهيئة المعاونـة، (كلية الهية

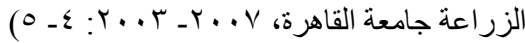

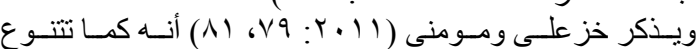

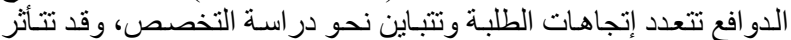

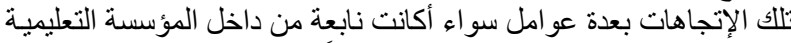

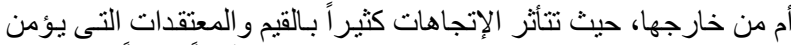

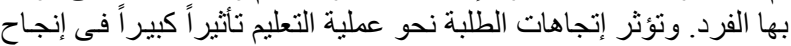

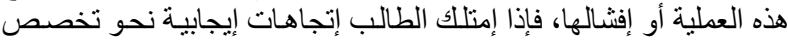

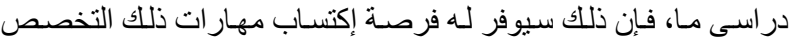

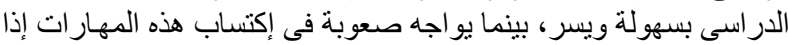

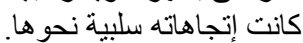

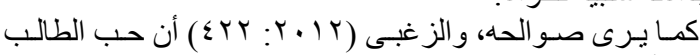

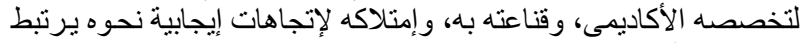

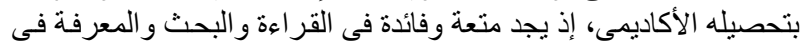

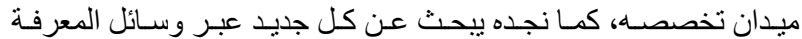
المختلفة، لكى يتغلب على جو انب الضعف لديه، ويعزز لدئ لديه جو انب القوة

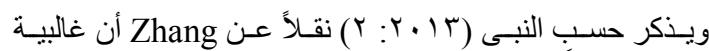
وينميها.

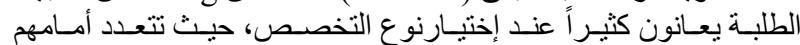

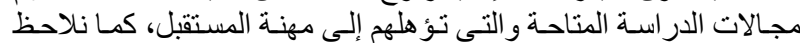

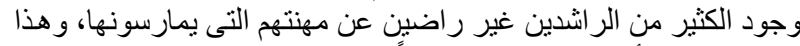

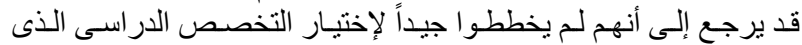

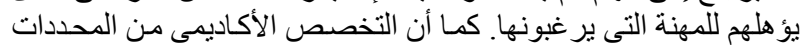

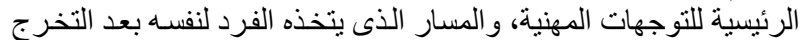

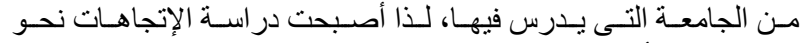

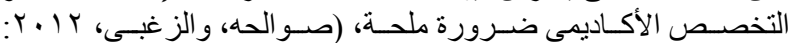

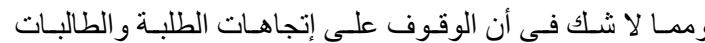

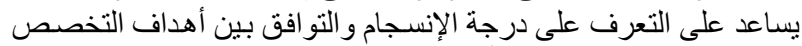

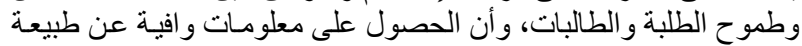

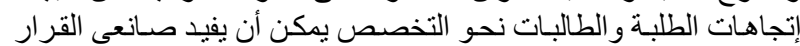

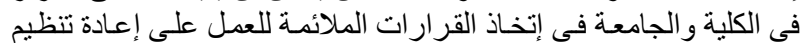

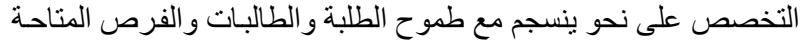

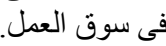
ويعتبر تخصص الإرشاد الزراعى من أهم التخصصات التطبيقية

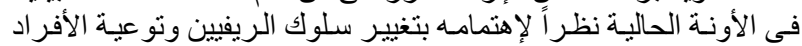

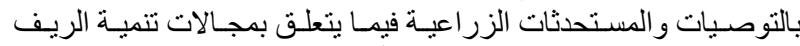

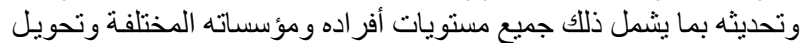

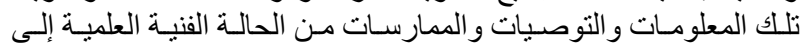

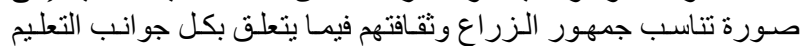

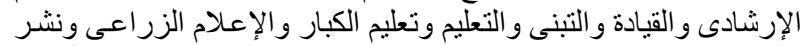

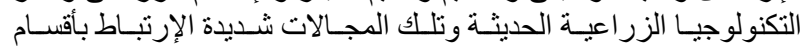

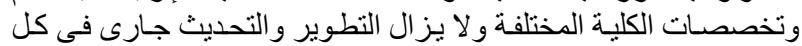

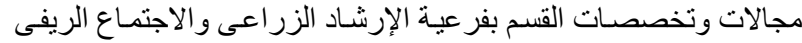

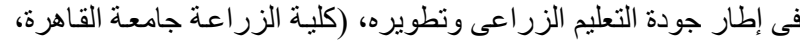

( $\varepsilon: Y$...

وتنحصر اهتمامات الإرشاد الزراعى فى توعية أهل الريف فيما

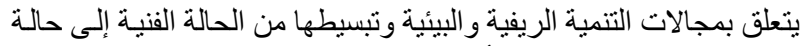

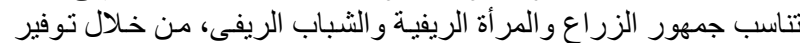

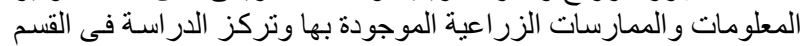

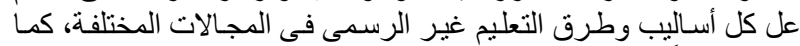

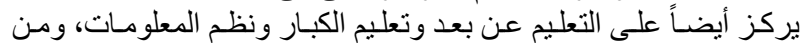

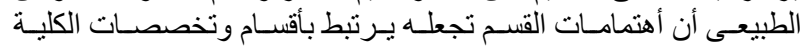

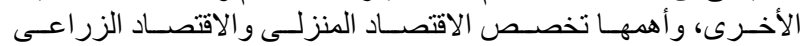
و المحاصيل و الصناعات الغذائية و الألبان و الإنتاج الحيو النى، حيث تشكل
الإلتـــاق بهـذا التخصـص دون القيـام بتـدعيم إتجاهـات الطلبـة نـــو هـذا

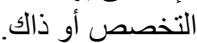

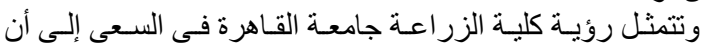

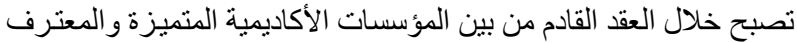

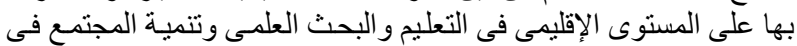

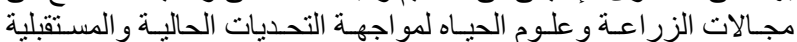

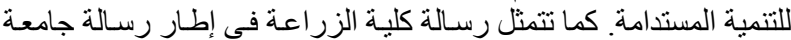

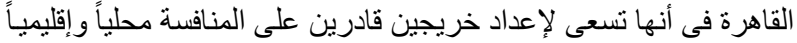

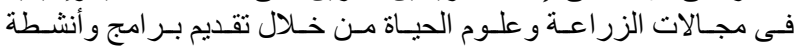

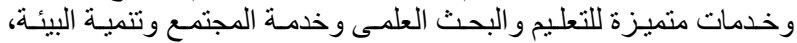

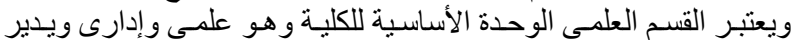

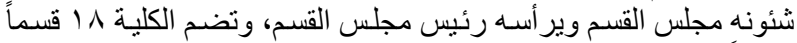

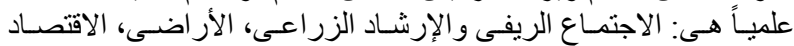

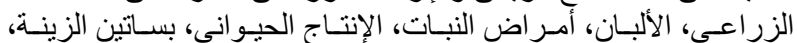

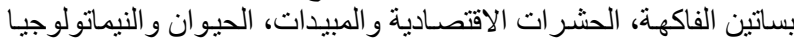

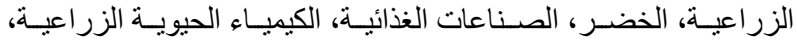

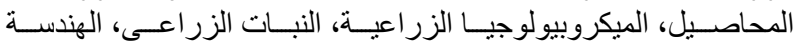

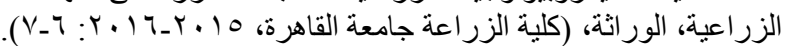

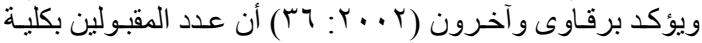

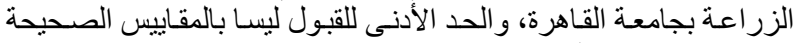

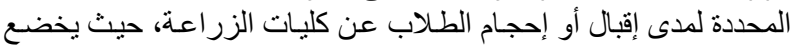

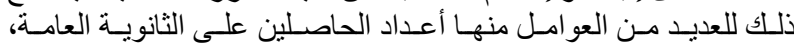

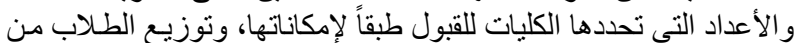

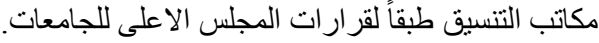

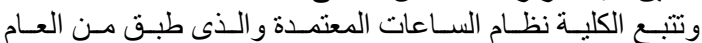

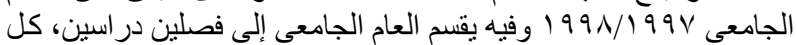

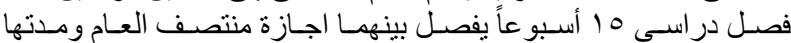

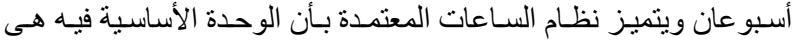

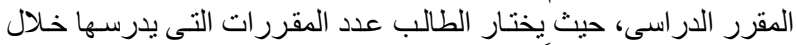

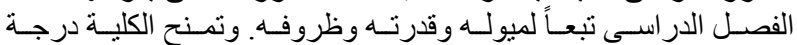

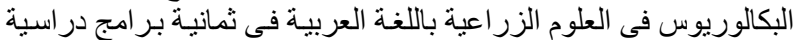

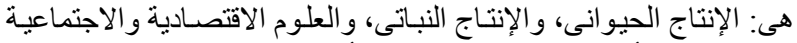

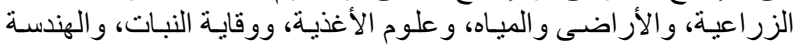

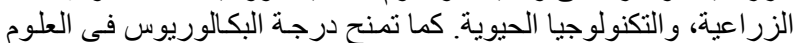

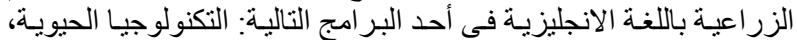

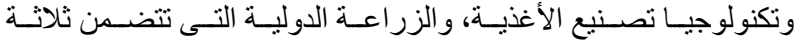

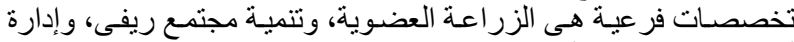

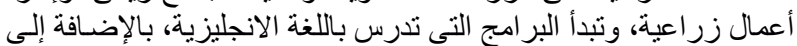

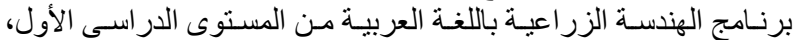

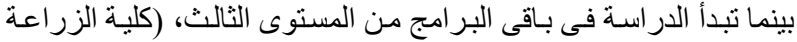

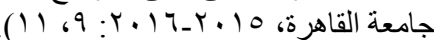

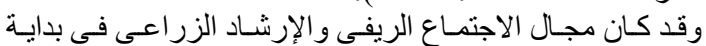

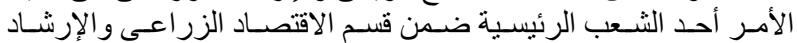

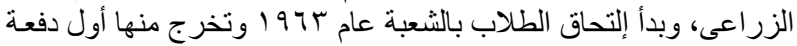

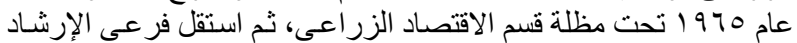

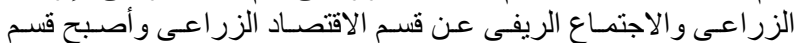

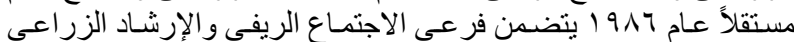

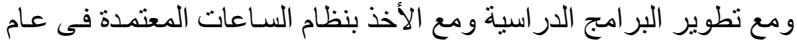

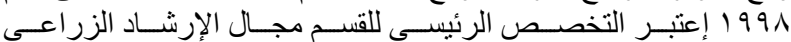

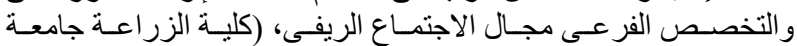

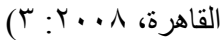

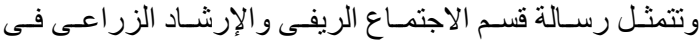

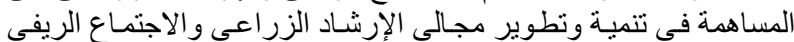

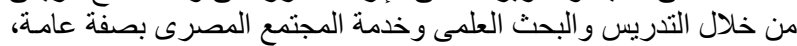

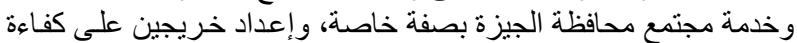

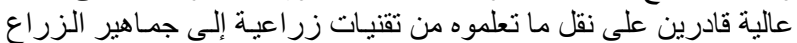

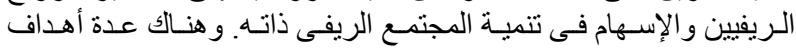

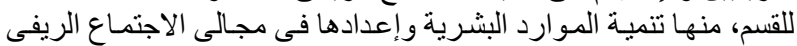

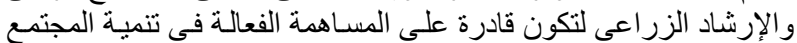

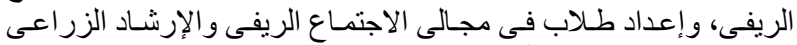

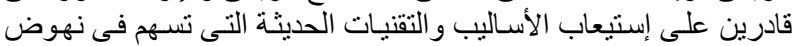

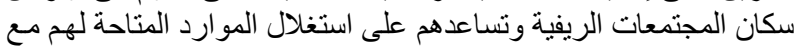




\section{J. Agric. Econom. and Social Sci., Mansoura Univ., Vol.7 (3), March ,2016}

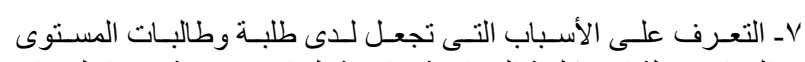

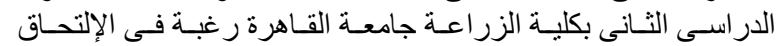
بتخصص الإرشاد الزراعى.

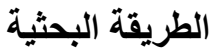

التعريـف الإجرائسى لإتجــاه الطلبـة والطالبـات نحـو تخصـص الإرشــاد

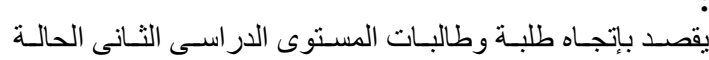
الزراعى:

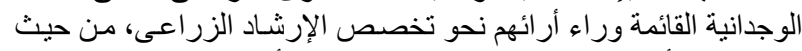

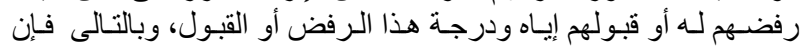

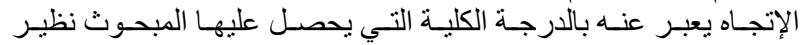
إستجابته لعدد عشرون عبارة متعلقة بالإتجاه نحو هذا الإندا التخصص. الفرض البحثي والإحصائى: الفئن

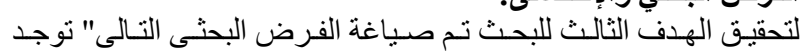

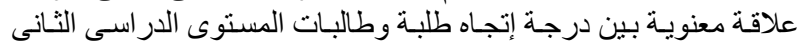

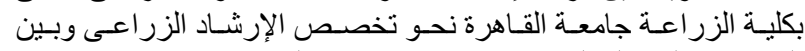

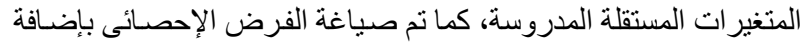

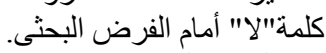

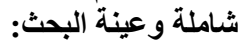

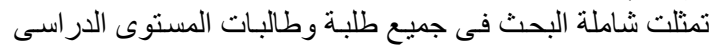

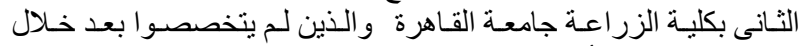

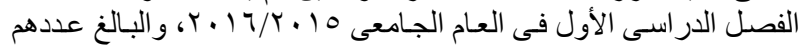

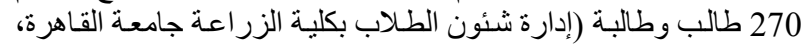

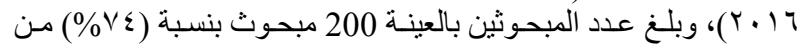
إجمالى الثاملة. منطقة البحث: البمالئ

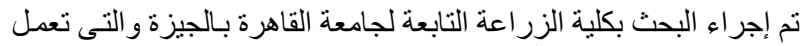

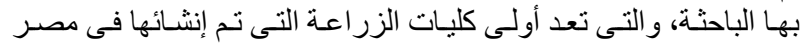

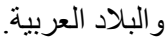
طريقة وأداة جمع البيانات:

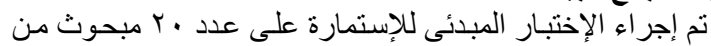

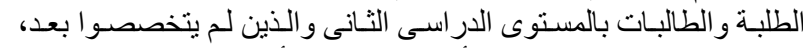

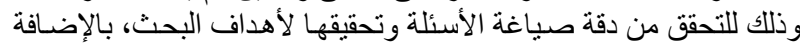

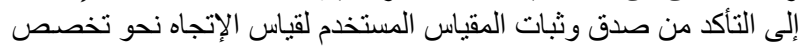

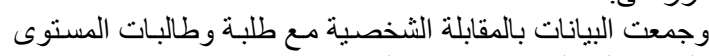

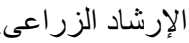

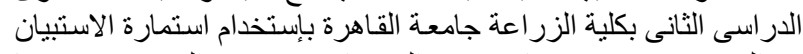

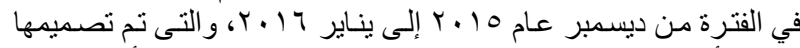

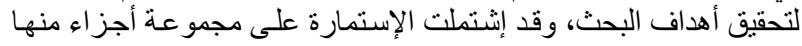

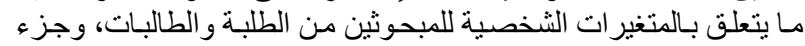

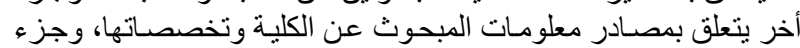

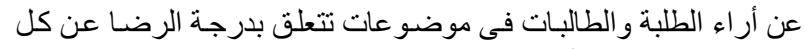

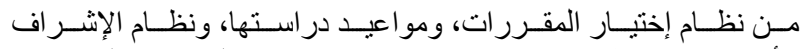

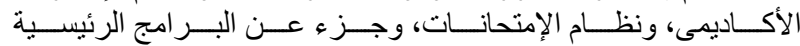

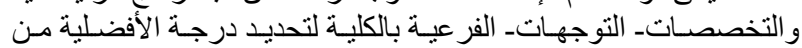

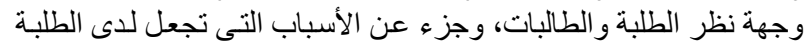

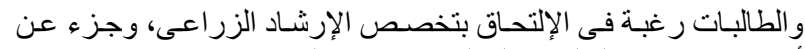

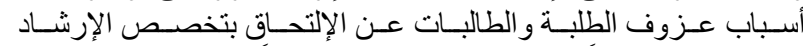

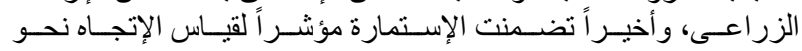

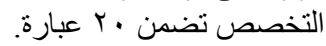

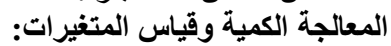

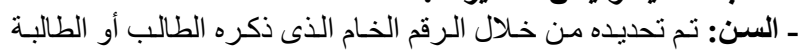

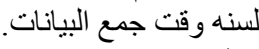

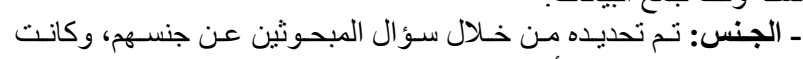

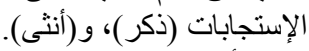

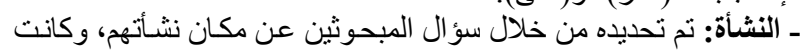

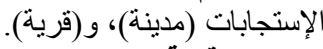

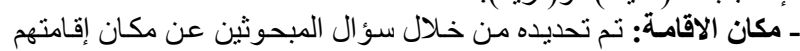
الحالية، وكانت الإستجابات (مع الأسرة)، و و(مكان إقامة أخر ).

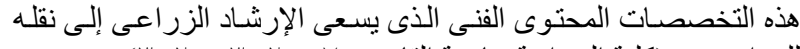

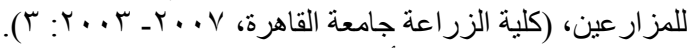

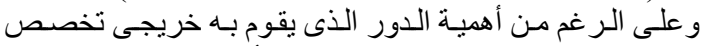

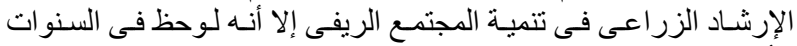

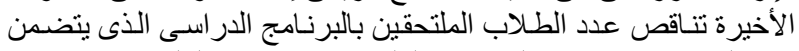

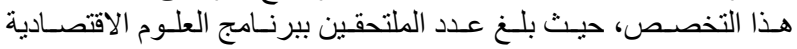

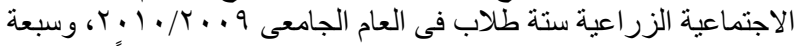

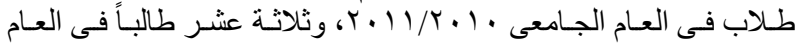

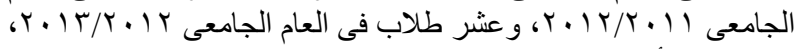

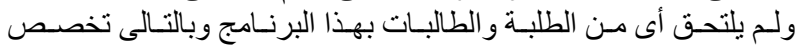

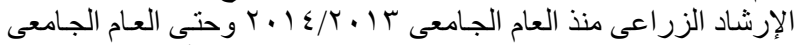

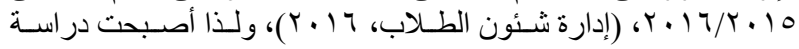

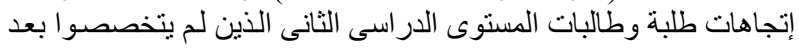

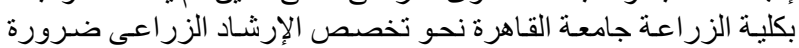

ولذلك تمثلت مشكلة البحث فى التساؤلات التالية: مـا هـى مصـادر

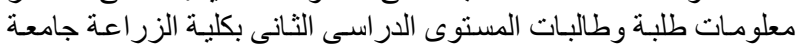

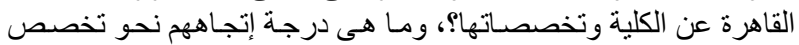

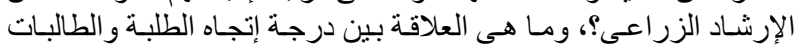

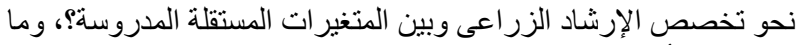

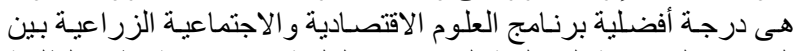

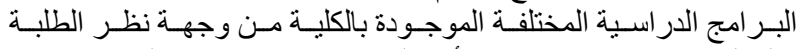

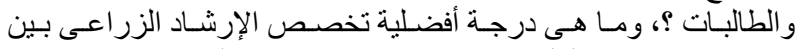

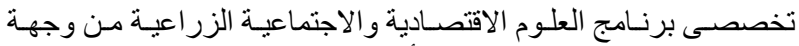

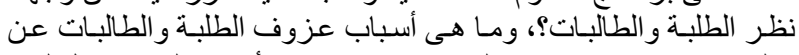

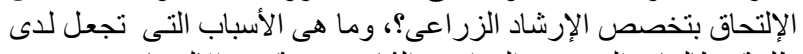

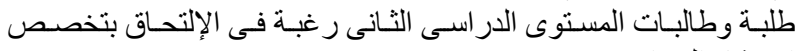

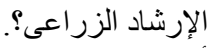

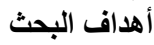

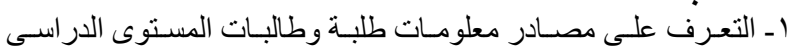

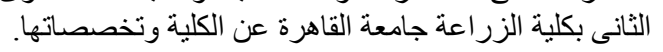

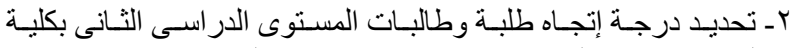

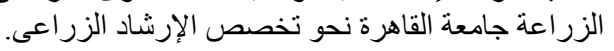

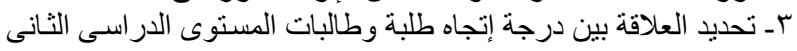

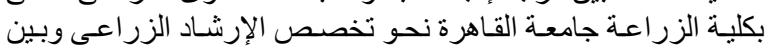

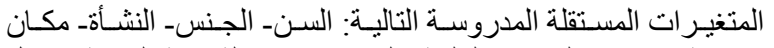

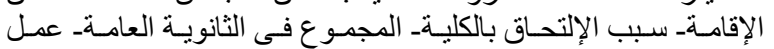

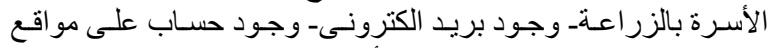

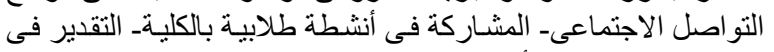

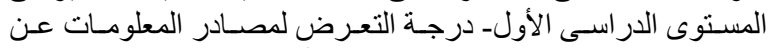

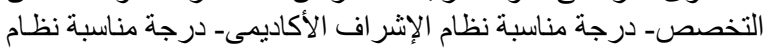

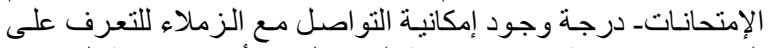

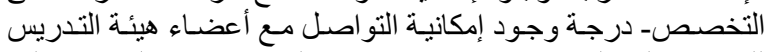

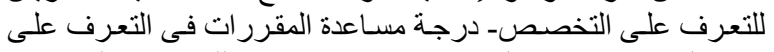

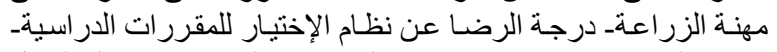

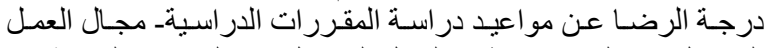

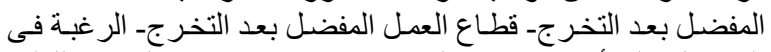

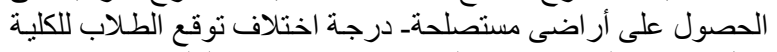

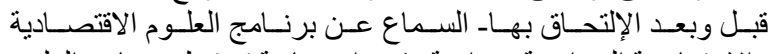

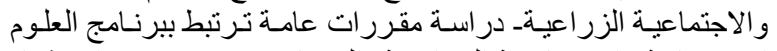

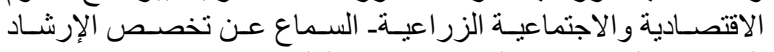

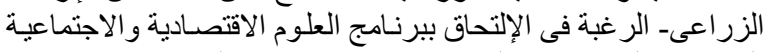

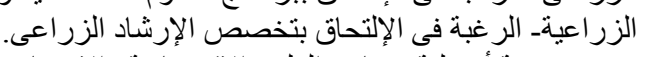

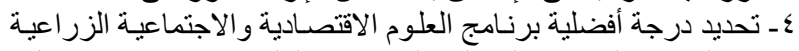

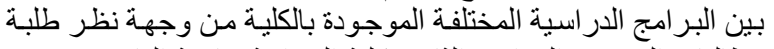

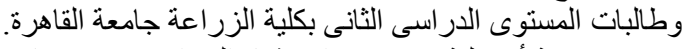

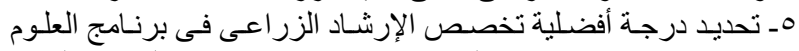

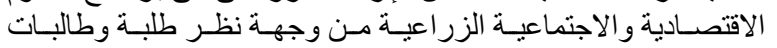

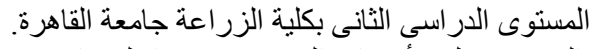

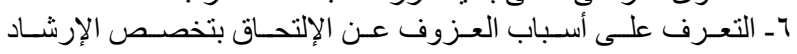

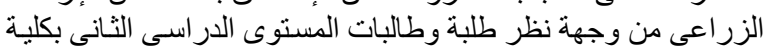
الزراعة جامعة القاهرة. 


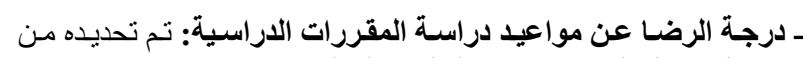

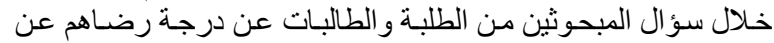

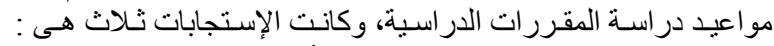

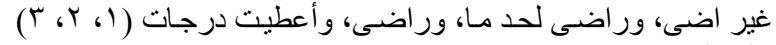

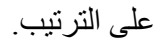

ـ مجال العمل المفضل بعد التخرج: تم تحديده من خلال سؤ ال المبحوثين

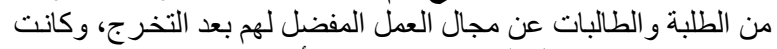

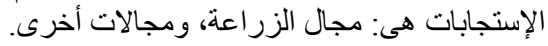

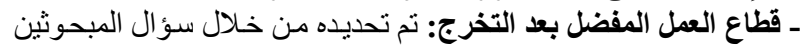

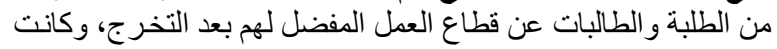

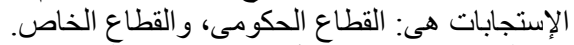

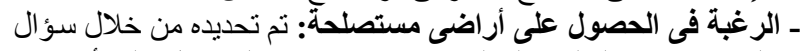

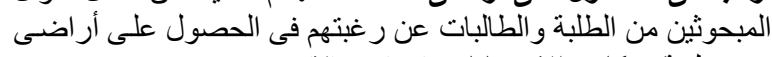

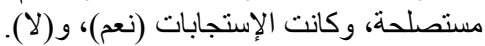

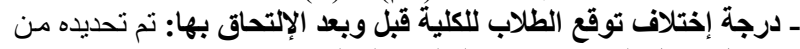

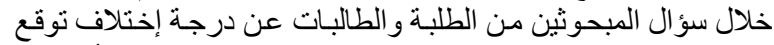

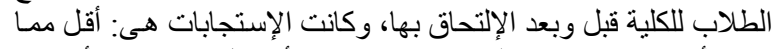

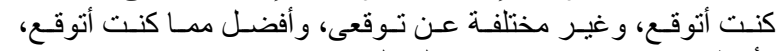

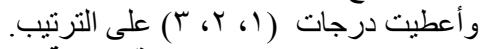

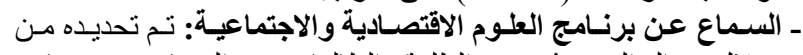

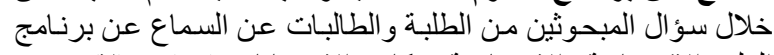

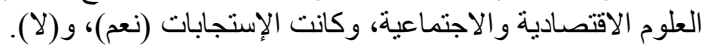

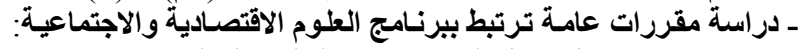

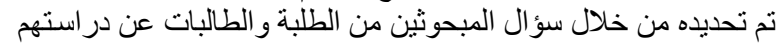

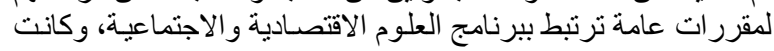

الإستجابات (نعم)، و و(لا).

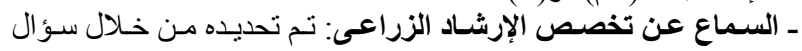

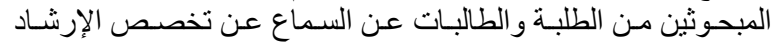

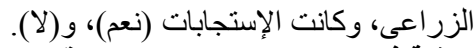

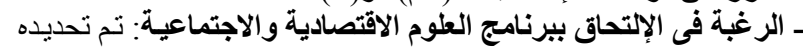

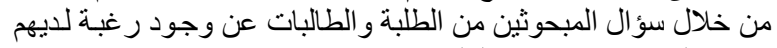

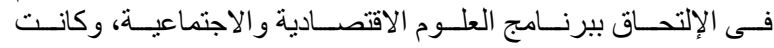

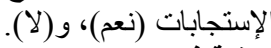

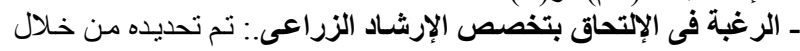

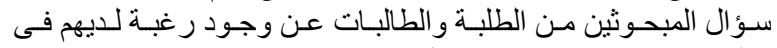

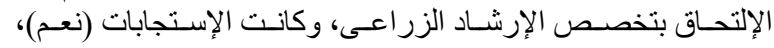

إتجاه الطلبة والطالبات نحو تخصص الإرشاد الزراعى:

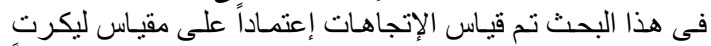

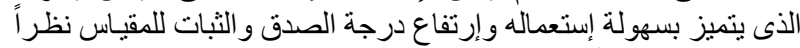

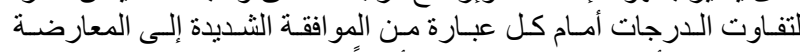

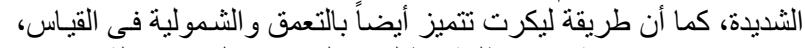

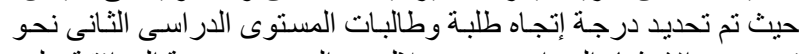

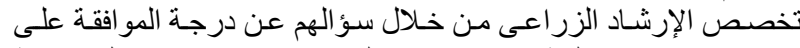

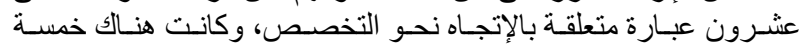

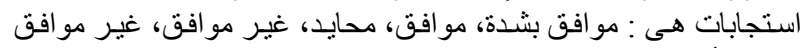

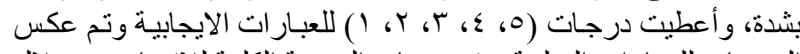

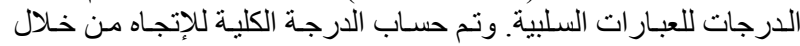

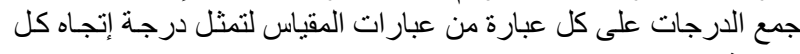

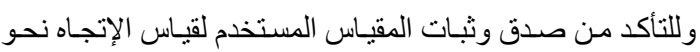

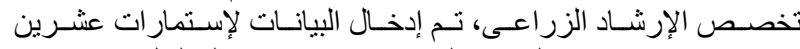

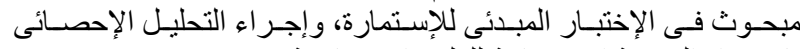

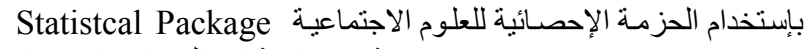
for Social Sciences (SPSS)

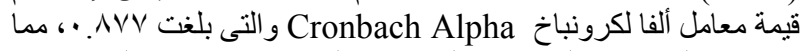

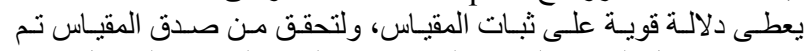

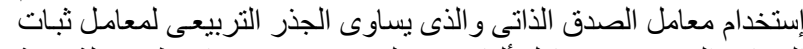

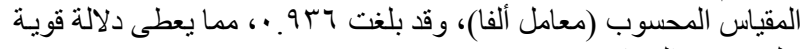

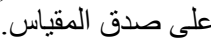

ـ سبب الإلتحاق بالكلية: تم تحديده من خلال سؤ ال المبحوثين عن أسباب

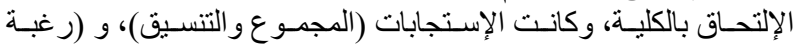

شخصية).

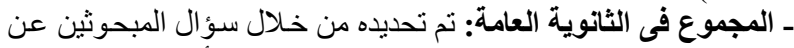

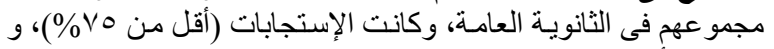

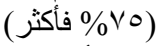

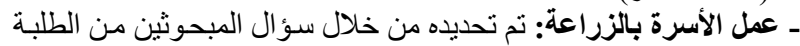

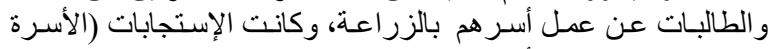

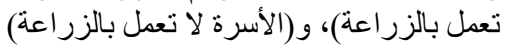

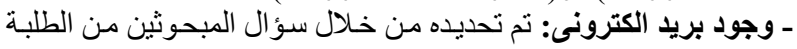

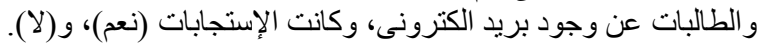

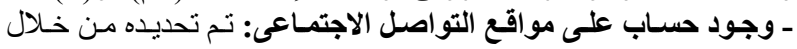

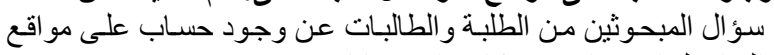

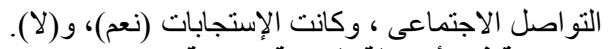

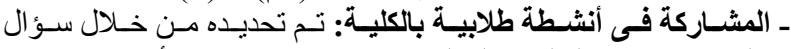

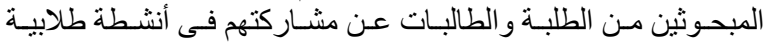

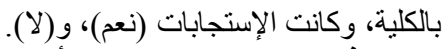

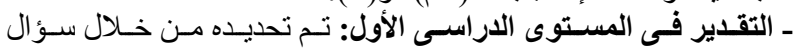

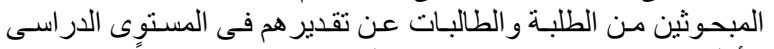

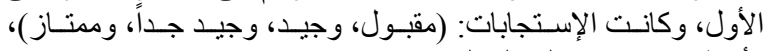

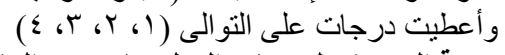

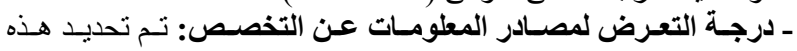

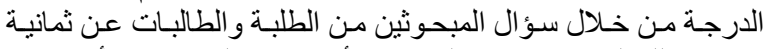

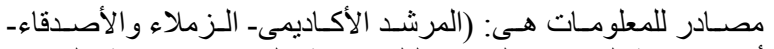

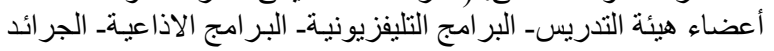

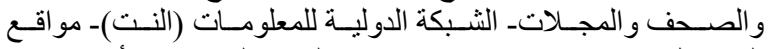

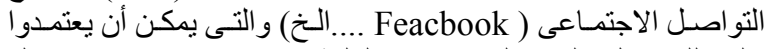

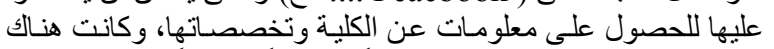

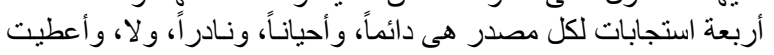

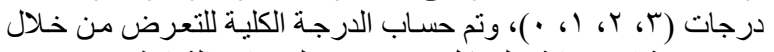

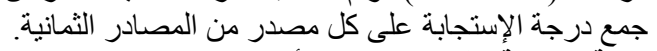

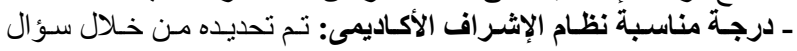

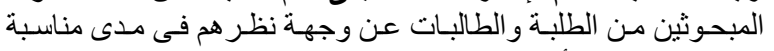

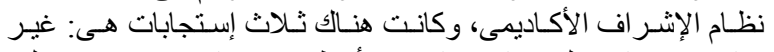

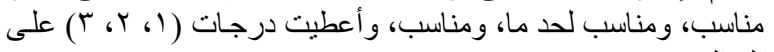
التو الىى. - مانب. ـ درجة مناسبة نظام الإمتحانـات: تم تحديده من خـلال سؤ ال المبحوثين

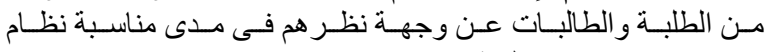

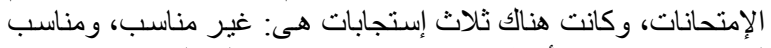

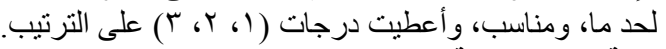

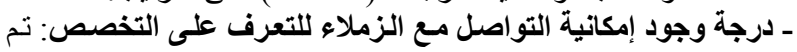

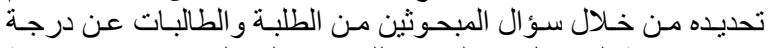

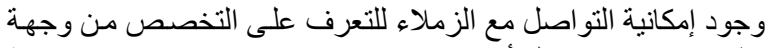

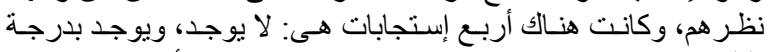

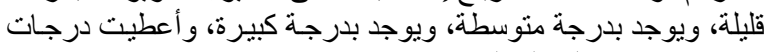

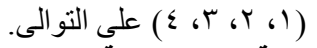

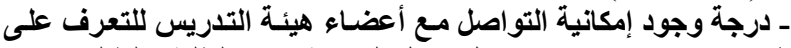

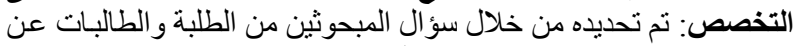

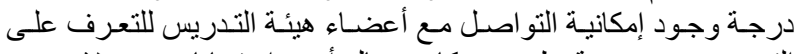

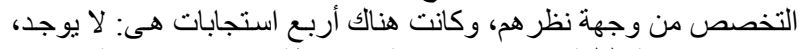

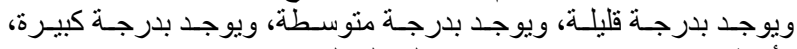

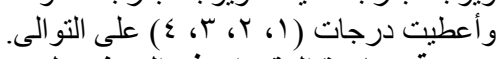

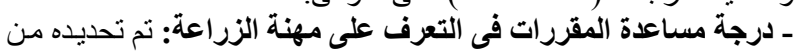

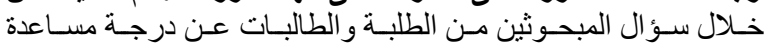

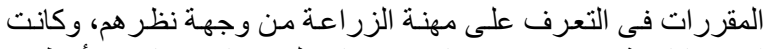

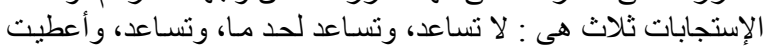

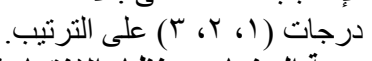

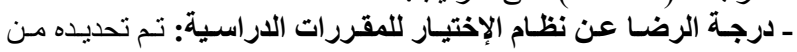

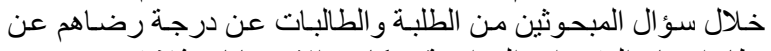

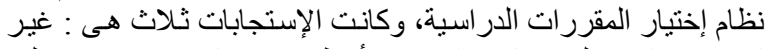

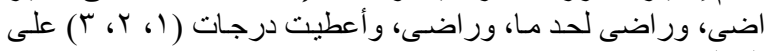

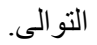




\section{J. Agric. Econom. and Social Sci., Mansoura Univ., Vol.7 (3), March ,2016}

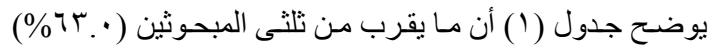

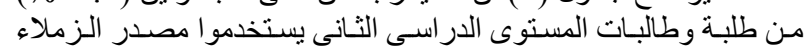

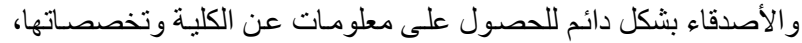

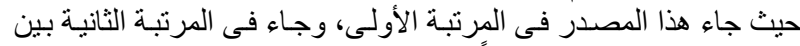

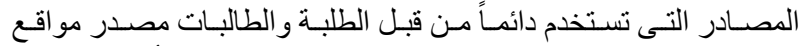

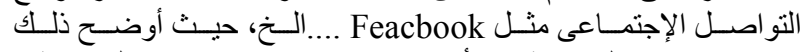

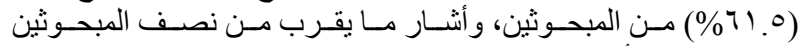

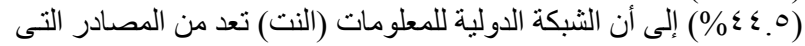

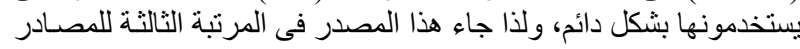

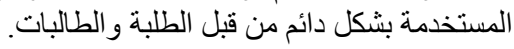

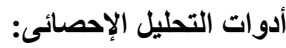

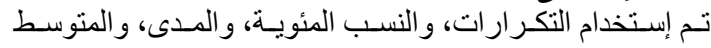

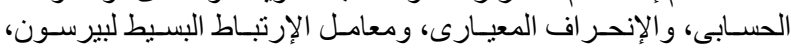
و إختبارمربع كاى فى عرض وتحليل البيانات.

النتائج ومناقشتها

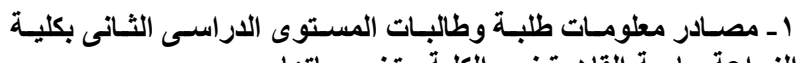
الزراعة جامعة القاهرة نحو الكلية وتخصصاتها.

جدول ( (1) توزيع المبحوثين من الطلبة والطالبـات وفقاً لمصـادر المعلومـات التى يستخذمونها للحصول على معلومـات عن الكلية وتخصصـاتها r... ن

\begin{tabular}{|c|c|c|c|c|c|c|c|c|c|}
\hline \multirow{2}{*}{\multicolumn{2}{|c|}{ الإجمالى }} & \multicolumn{8}{|c|}{ درجة إستخدام المصدر } \\
\hline & & \multicolumn{2}{|c|}{ ע } & \multicolumn{2}{|c|}{ ' نادراً } & \multicolumn{2}{|c|}{ أحياناً } & \multicolumn{2}{|c|}{ 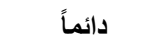 } \\
\hline$\%$ & عدد & $\%$ & عدد & $\%$ & عدد & $\%$ & عدد & $\%$ & عدد \\
\hline 100 & 200 & ro." & $V$. & $r \cdot 0^{\circ}$ & 71 & rq. & 01 & 0.0 & 11 \\
\hline 100 & 200 & $r_{.}$. & $\varepsilon$ & r. & 7 & r.. & $7 \varepsilon$ & שים & Trו \\
\hline 100 & 200 & 11.0 & r & 11. & Tr & $\varepsilon r .0$ & $\wedge \mathrm{V}$ & $r v$. & 0\{ \\
\hline 100 & 200 & $7 r .0$ & iro & 19.0 & rq & Ir. & $r \varepsilon$ & 7. & Ir \\
\hline 100 & 200 & 77. & ITr & $r \cdot$. & $\varepsilon$ & Ir. & $Y \varepsilon$ & r. & $\varepsilon$ \\
\hline 100 & 200 & 09.0 & 119 & 19.0 & rq & IV. & & $\varepsilon$. & $\wedge$ \\
\hline 100 & 200 & 11. & rr & $V_{.}$. & $1 \varepsilon$ & rv.o & vo & $\varepsilon \leqslant .0$ & 19 \\
\hline 100 & 200 & 0.0 & 11 & 9.0 & 19 & r.o & $\varepsilon V$ & 71.0 & Tr \\
\hline
\end{tabular}

مصادر المعلومات

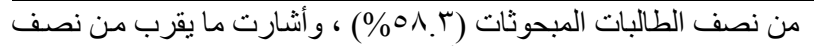

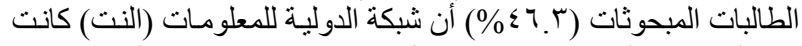

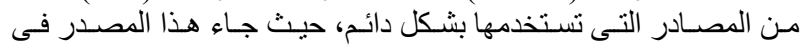

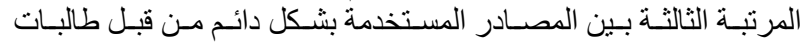

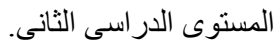

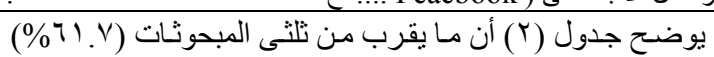

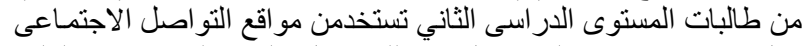

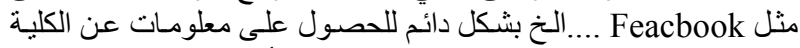

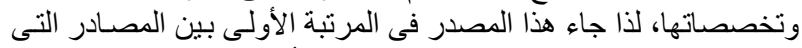

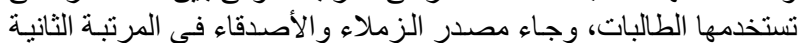

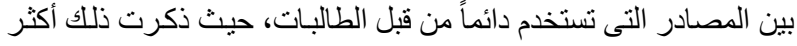
جدول (r) توزيع المبحوثين من الطالبات وفقاً لمصادر المطلومات التى تستخذمها للحصول على معلومات عن الكلية وتخصصاتها ن= . 11

\begin{tabular}{|c|c|c|c|c|c|c|c|c|}
\hline \multirow{2}{*}{\multicolumn{2}{|c|}{ الإجمالى }} & \multirow{2}{*}{\multicolumn{7}{|c|}{ درجة إستخدام المصدر }} \\
\hline & & y & & & & & & \\
\hline$\%$ & عدد & $\%$ & عدد & $\%$ & عدد & $\%$ & عدد & $\%$ \\
\hline 100 & 11. & $r \cdot{ }^{\prime} \cdot$ & Tr & $r . \wedge$ & ro & rI.^ & ro & $7 . \varepsilon$ \\
\hline 100 & 11. & T.7 & $\varepsilon$ & $r .7$ & $\varepsilon$ & $r \leqslant .0$ & ऍᄉ & $0 \wedge . r$ \\
\hline 100 & 11. & 9.1 & 1. & 10.0 & IV & $\sum V, Y$ & or & $r \wedge . r$ \\
\hline 100 & 11. & 71. & TV & T.ד. & $r T$ & $11 . \wedge$ & Ir & T. \\
\hline 100 & 11. & $T V . r$ & $V \leq$ & $r \cdot$. & Yr & $1 \cdot$. & 11 & Y.V \\
\hline 100 & 11. & 09.1 & 70 & $r \cdot . q$ & r & 10.0 & IV & $\varepsilon .0$ \\
\hline 100 & 11. & V.r & $\wedge$ & ^.r & 9 & $r \wedge . r$ & $\varepsilon r$ & $\varepsilon 7 . r$ \\
\hline 100 & 11. & $7 . \varepsilon$ & V & 7. $\varepsilon$ & V & ro. 0 & rA & $11 . V$ \\
\hline
\end{tabular}

مصادر المعلومات

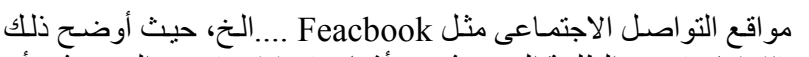

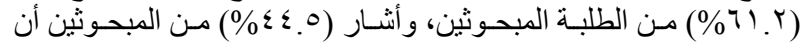

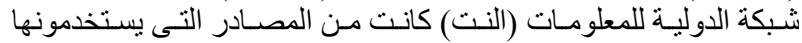

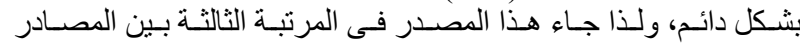
المستخدمة بشكل دائم من قبل طلبة المستوى الدار استى الثانى.

Eבد
$Y$
$7 \leq$
$r$
$\leq$
$r$
0
01
71
المرشد الأكاديمى

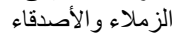
أعضاء هيئة التدريس والاهنئ

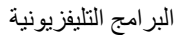

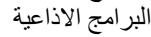
الجر ائد و الصجف الصغئ والمجلات

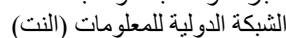

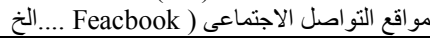

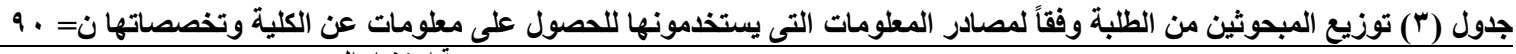

\begin{tabular}{|c|c|c|c|c|c|c|c|c|c|}
\hline \multirow{2}{*}{\multicolumn{2}{|c|}{ الإجمالى }} & \multicolumn{8}{|c|}{ درجة إستخدام المصدر } \\
\hline & & \multicolumn{2}{|c|}{$\gamma$} & \multicolumn{2}{|c|}{ نادراً } & \multicolumn{2}{|c|}{ أحساناً } & \multicolumn{2}{|c|}{ دائماً } \\
\hline$\%$ & عدد & $\%$ & عدد & $\%$ & عدد & $\%$ & عدد & $\%$ & عدد \\
\hline 100 & 9. & $\varepsilon 1.1$ & $r v$ & Y^. ${ }^{9}$ & YT & Yo.7 & Tr & $\varepsilon . \varepsilon$ & $\varepsilon$ \\
\hline 100 & 9. & $\therefore$ & . & $r . r$ & r & rA.q & YY & 71.9 & $T r$ \\
\hline 100 & 9. & $1 \leq \varepsilon$ & $1 T$ & Y). & 19 & rᄉ. $q$ & ro & Y0.T & Tr \\
\hline 100 & 9. & $7 \leqslant 0$ & 01 & $1 \leqslant . \varepsilon$ & Ir & Ir.r & 11 & 1.9 & $\wedge$ \\
\hline 100 & 9. & $7 \leqslant 0$ & 01 & $r \cdot$. & 11 & $1 \leqslant . \varepsilon$ & r & 1.1 & 1 \\
\hline 100 & 9. & 7. & $0 \leqslant$ & $\mid V \wedge$ & 17 & 11.9 & IV & r & $r$ \\
\hline 100 & 9. & 10.7 & $1 \leq$ & 0.0 & ○ & r.. V & אי & $\varepsilon r . Y$ & rᄉ \\
\hline 100 & 9. & $\varepsilon . \varepsilon$ & $\varepsilon$ & ח.r & ir & ri. 1 & 19 & $\pi$ & 00 \\
\hline
\end{tabular}

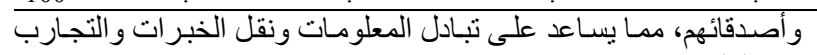
عن الكلية وتخصصاتها.

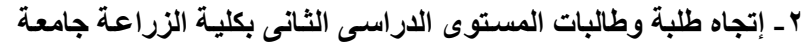

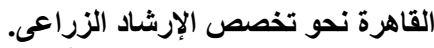

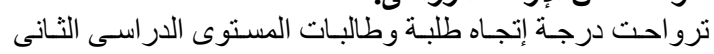

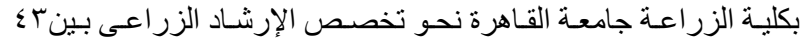

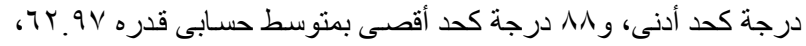

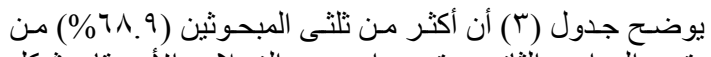

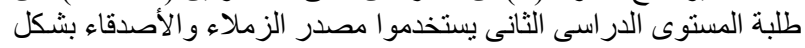

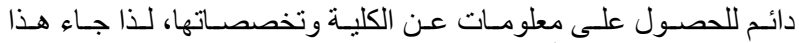

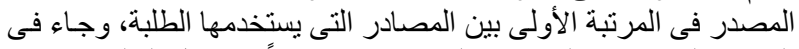

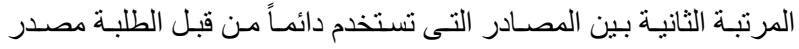

\begin{tabular}{|c|c|}
\hline عدد & مصادر المعلومات \\
\hline$\xi$ & المرشد الأكاديمى \\
\hline Tr & 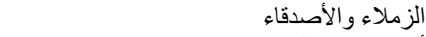 \\
\hline r & أعضاء هيئة التدريس \\
\hline$\wedge$ & البر امج التليفزيونية \\
\hline 1 & البر امج الاذاعية \\
\hline r & الجر ائد و الصجف و المجلات \\
\hline ru & الثبكة الدولية للمعلومات (النت) \\
\hline 00 & مو اقع التو اصل الاجتماعى ( Feacbook ....الخ \\
\hline
\end{tabular}

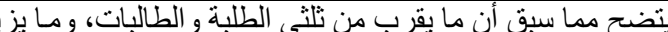

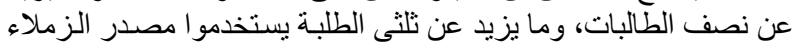

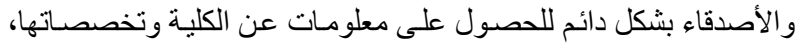

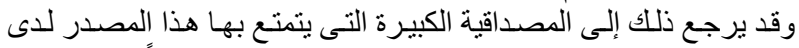

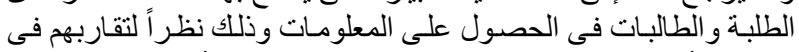

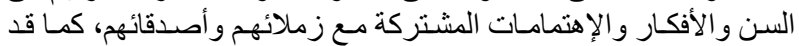
يرجع إلى إمكانية وسهولة التفاعل و التو اصنل اليومى بينهم وبين زملائهم 


\section{Sahar A. Hikel}

ويبين نفس الجدول أن أكثر من ثلث المبحوثين من طلبة المستوى

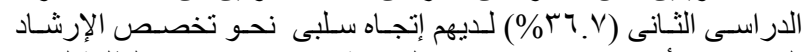

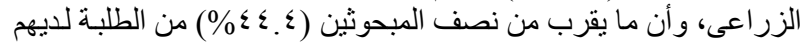

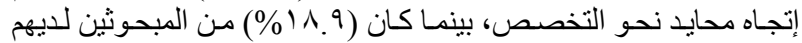

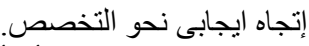
يتضح مما سبق أن أكثر من نصف البه المبحوثين سو اءواً من الطلبة

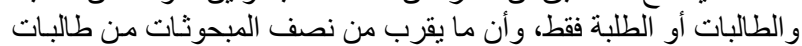

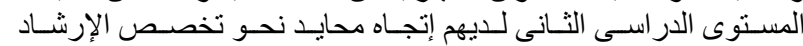

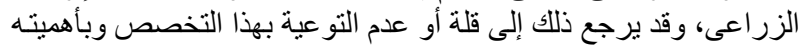

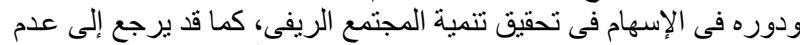

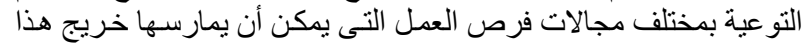
التخصص فى الحياه العملية و المهنية بعد ذلك.

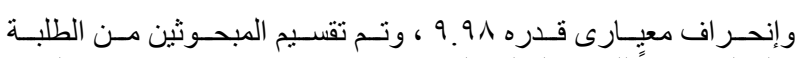

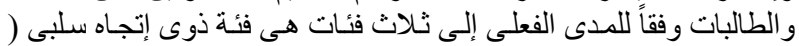

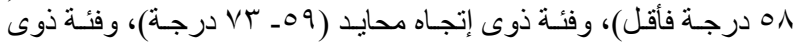

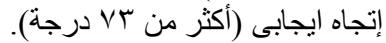

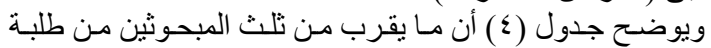

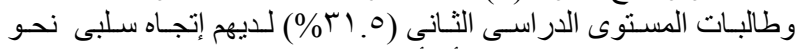

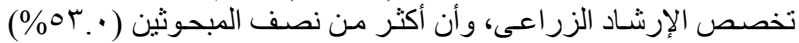

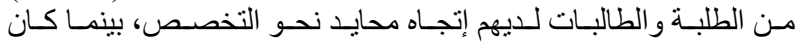

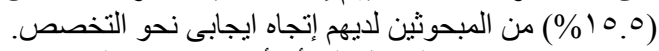

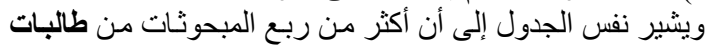

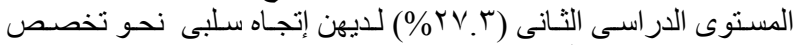

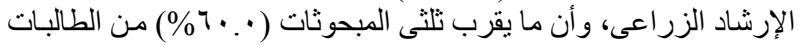

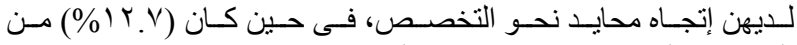
المبحوثات لايهن إتجاه ايجابى نحو التخصص.

\begin{tabular}{|c|c|c|c|c|c|c|}
\hline \multicolumn{2}{|c|}{ الطلبة والطالبات } & \multicolumn{2}{|c|}{ الطلبة } & \multicolumn{2}{|c|}{ الطالبات } & \multirow{2}{*}{ فئات الإتجاه نحو تخصص الإرشاد الزراعى } \\
\hline$\%$ & عدد & $\%$ & عدد & $\%$ & عدد & \\
\hline T1.0 & Tr & r.. & Tr & TV.r & $r \cdot$ & إتجاه سلبى (^ه درجة فأقل) \\
\hline or. & 1.7 & $\varepsilon \varepsilon \varepsilon$ & $\varepsilon$ & $\because \cdot$ & 74 & إتجاه محايد ( هـ ـ r V درجة) \\
\hline 10.0 & r & 11.9 & iv & IY.V & $1 \varepsilon$ & إتجاه ايجابى (أكثر من VT درجة) \\
\hline $1 \ldots$ & r... & $1 \ldots$ & 9. & $1 \ldots$ & 11. & \\
\hline
\end{tabular}

تخصص الإرشاد الزر اعى كمتغير تابع وبين المتغيرات المستقلة الكمية

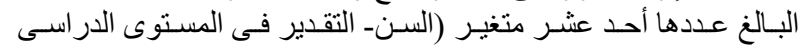

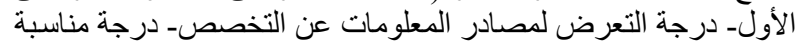

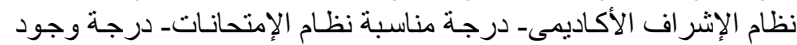

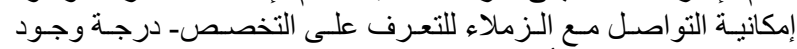

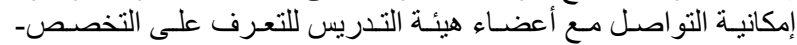

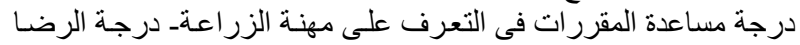

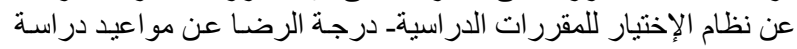

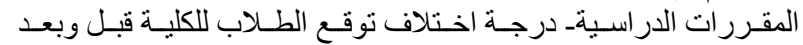

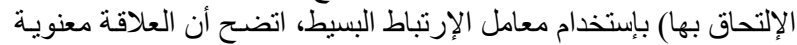

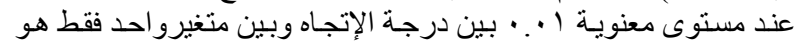

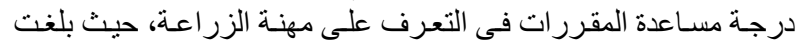

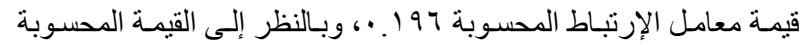

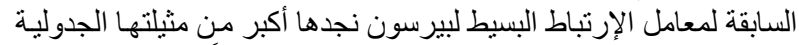

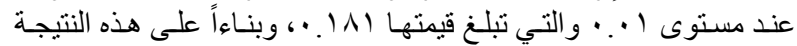

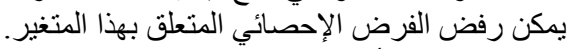

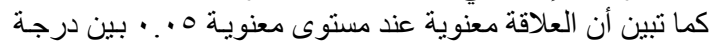

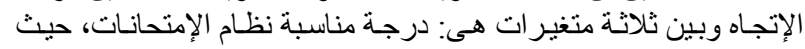

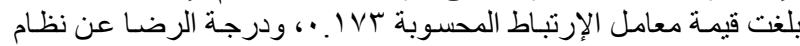

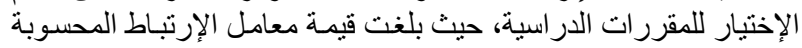

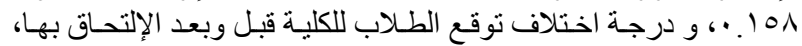

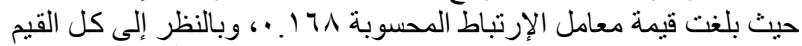

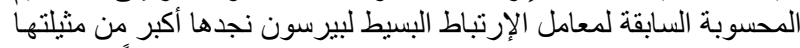

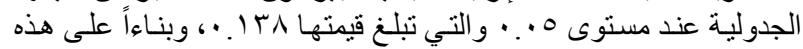
النتيجة يمكن رفض الفرض الإحصـائي المتعلق بهذه المتغير اتئ المنات المستقلة

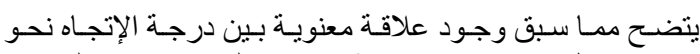
الثلاث.

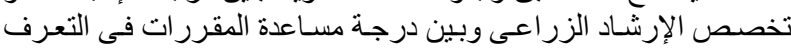

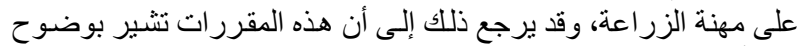

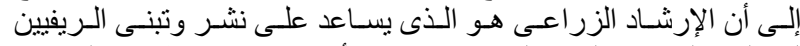

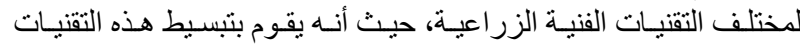

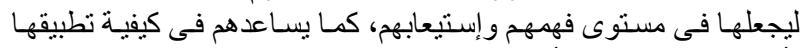

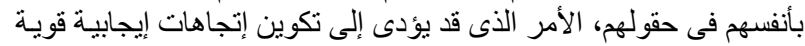

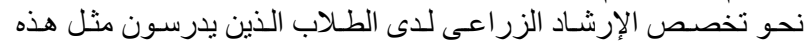

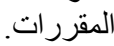

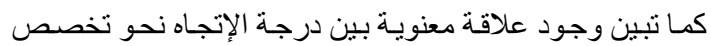

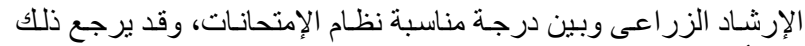

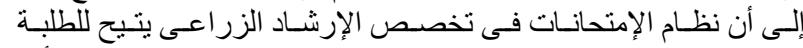

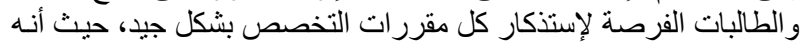

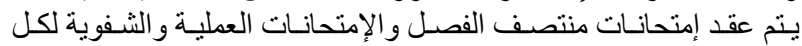
المقررات قبل عقد الإمتحانات النظرية لهذه المقررات، كما أنه توجد فترة النقات

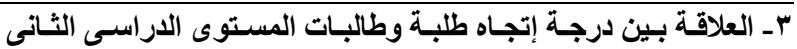

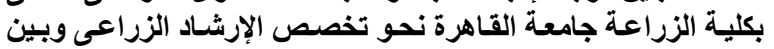
المتغيرات المستقلة المدروسة جامعة الماهة

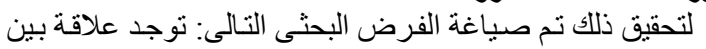

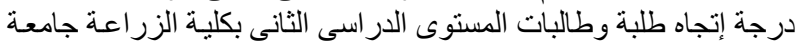

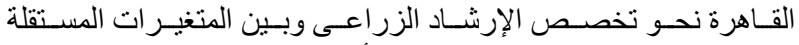

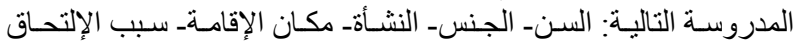

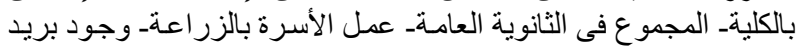

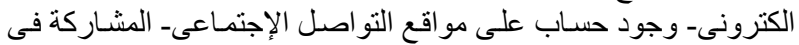

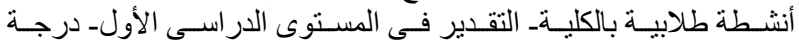

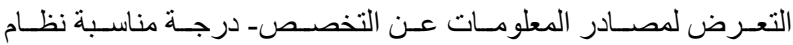

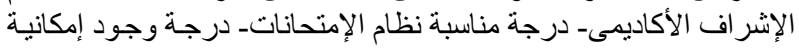

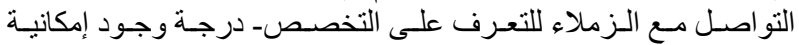

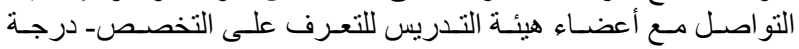

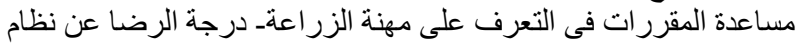

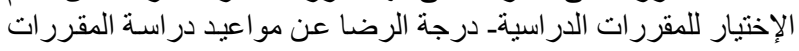

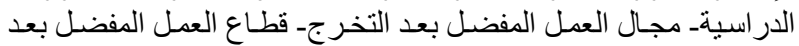

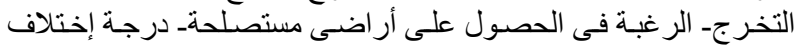

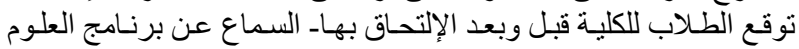

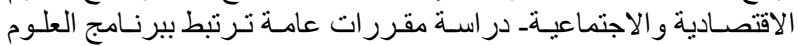

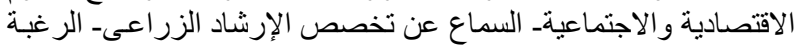

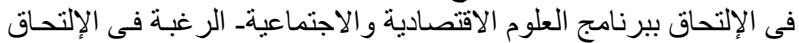

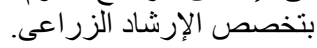

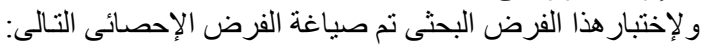

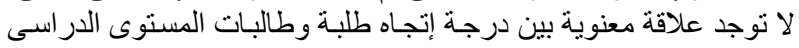

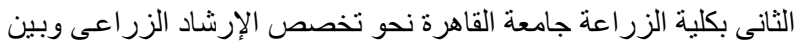

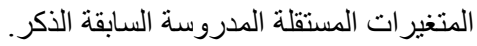

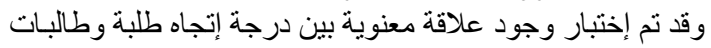

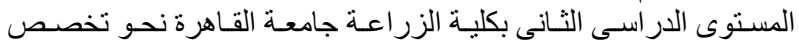

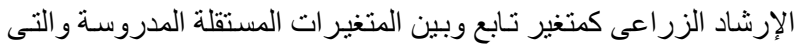

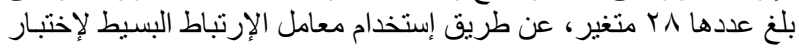

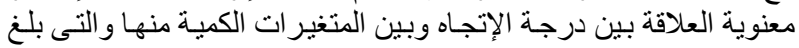

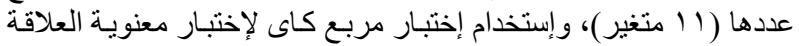

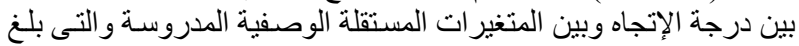

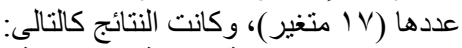

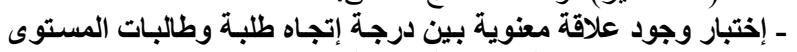

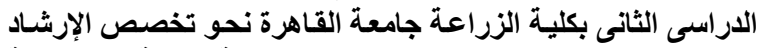

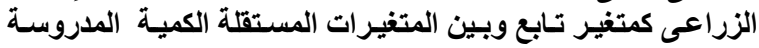

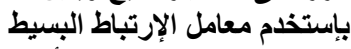

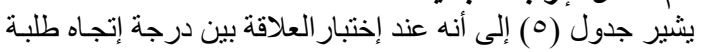

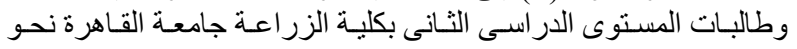




\section{J. Agric. Econom. and Social Sci., Mansoura Univ., Vol.7 (3), March ,2016}

- إختبار وجود علاقة معنويـة بين درجـة إتجاه الطالبـات نحو تخصص الزئل

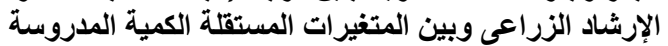

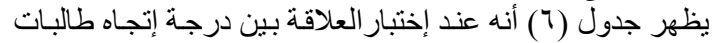

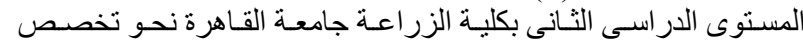

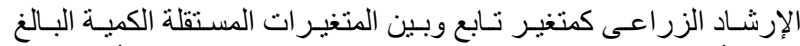

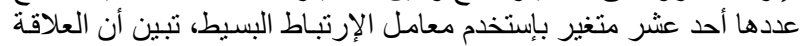

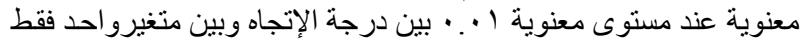

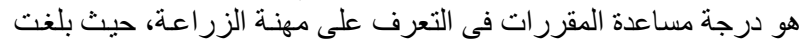

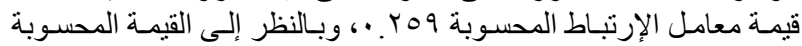

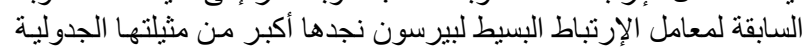

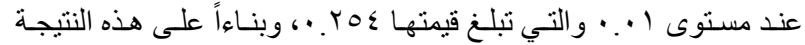

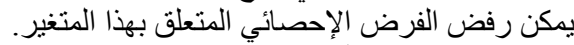

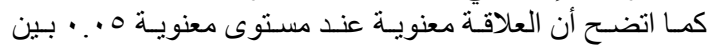

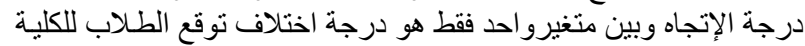

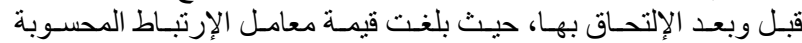

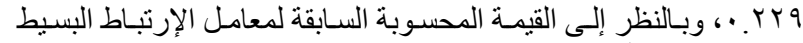

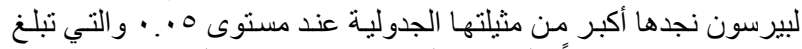

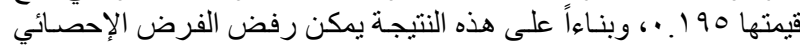

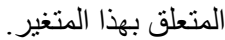

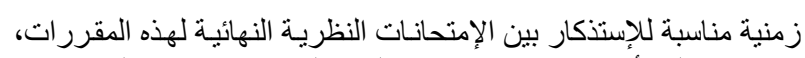

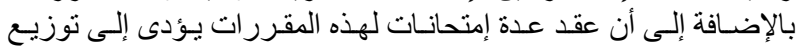

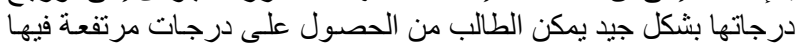

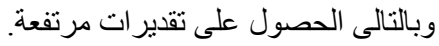

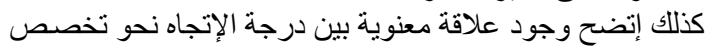

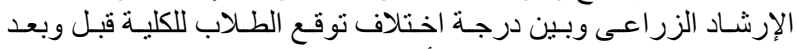

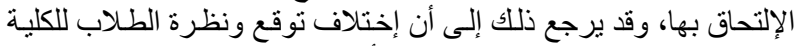

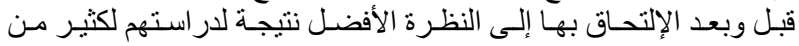

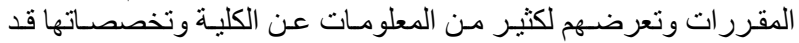

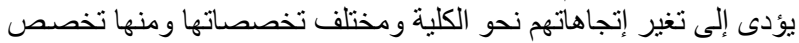
الإرشاد الزر اعى، الأمر الذى قد يؤدى إلى تكوين إتجاه إيجابى لديهم نحو

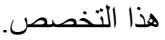

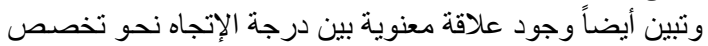

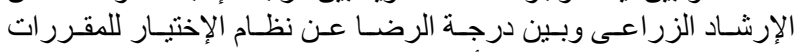

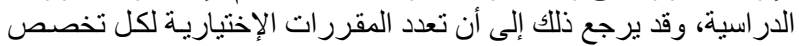

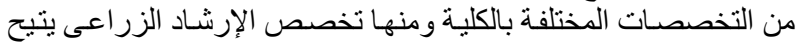

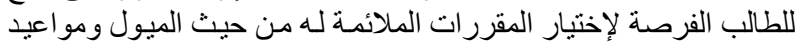

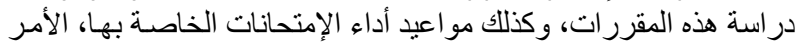

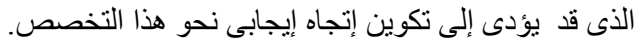

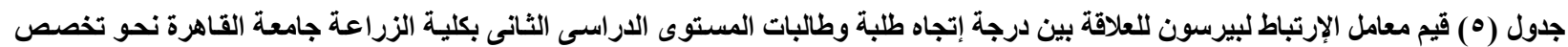

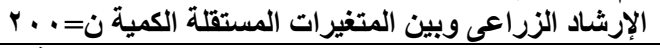

\begin{tabular}{|c|c|c|}
\hline قيم معامل الإرتباط & المتغيرات المستقلة الكمية & $\hat{r}$ \\
\hline .111 & 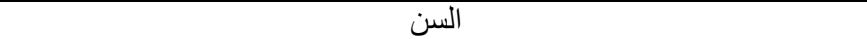 & $\overline{1}$ \\
\hline .111 & التقدير فى المستوى الدراسى الأول & r \\
\hline .111 & درجة التعرض لمصادر المعلومات عن التخصص & r \\
\hline .117 & درجة مناسبة نظام الإشر اف الأكاديمى & $\varepsilon$ \\
\hline$* . I V T$ & درجة مناسبة نظام الإمتحانات & 0 \\
\hline$\because \cdots \wedge$ & درجة وجود إمكانية التو اصل مع الزملاء للتعرف على التخصص & 7 \\
\hline$\because \leqslant q$ & درجة وجود إمكانية التو اصل مع أعضناء هيئة التدريس للتعرف على التخصص & $\checkmark$ \\
\hline$* * .197$ & درجة مساعدة المقررات فى التعرف على مهنة الزراعة & $\wedge$ \\
\hline$* .101$ & درجة الرضا عن نظام الإختيار للمقررات الدر اسية & 9 \\
\hline .07 & درجة الرضا عن مو اعيد دراسة المقررات الدر اسية & 1 . \\
\hline$* .17 \wedge$ & درجة اختلاف توقع الطلاب للكلية قبل وبعد الإلتحاق بها & 11 \\
\hline
\end{tabular}

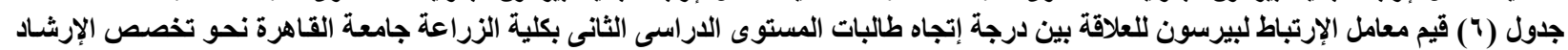

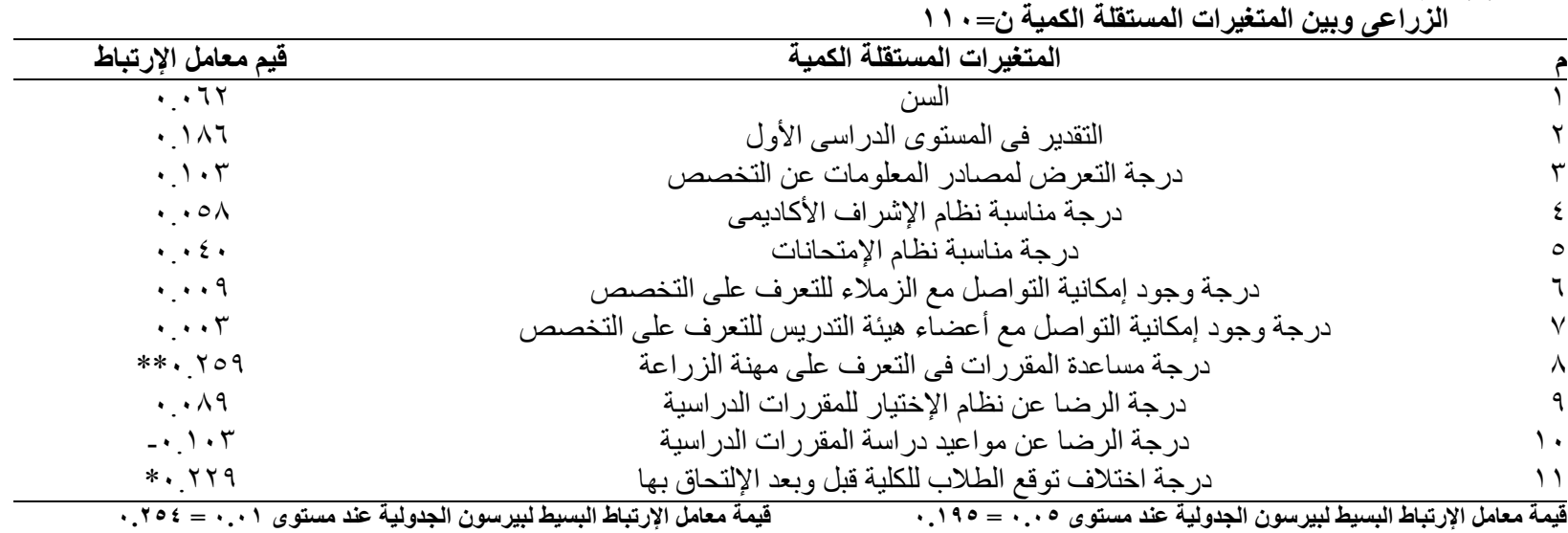

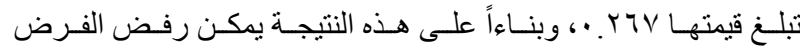

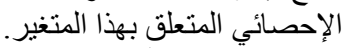

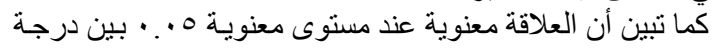

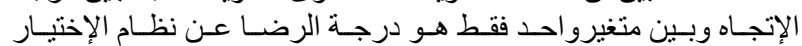

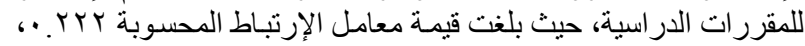

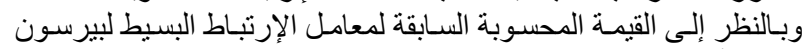

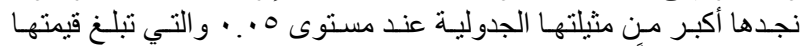

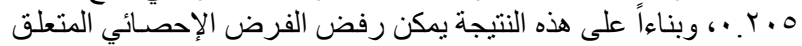

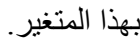

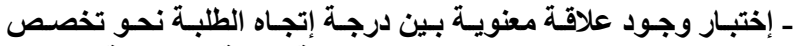

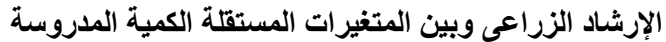

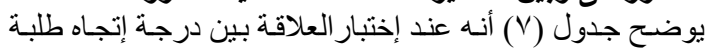

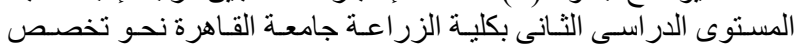

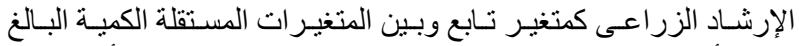

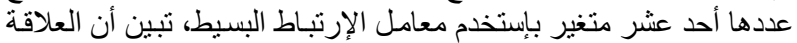

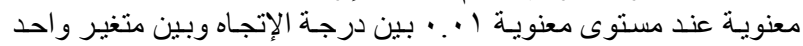

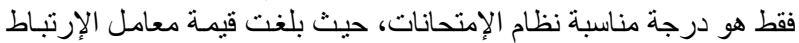

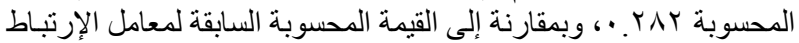

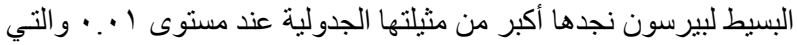


جدول (V) قيم معامل الإرتباط لبيرسون للعلاقة بين درجة إتجاه طلبة المستوى الدراسى الثانى بكلية الزراعة جامعة القاهرة نحو تخصص الإرشـاد

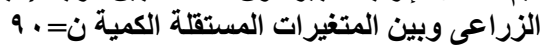

\begin{tabular}{|c|c|c|}
\hline 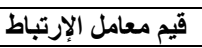 & المتغيرات المستقلة الكمية & ? \\
\hline .100 & السن & 1 \\
\hline$\therefore$ or & التقدير فى المستوى الدراسى الأول & r \\
\hline rri. & درجة التعرض لمصادر المعلومات عن التخصص & r \\
\hline .178 & 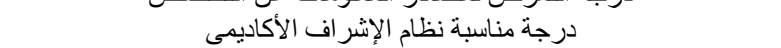 & $\varepsilon$ \\
\hline **. ratr & درجة مناسبة نظام الإمتحانات & \\
\hline$\because \cdot 1$ & درجة وجود إمكانية التو اصل مع الزملاء للتعرف على التخصص & \\
\hline$\because 94$ & درجة وجود إمكانية التو اصصل مع أعضاء هيئة التدريس للتعرف على التخصص & \\
\hline $.1 \leq 9$ & 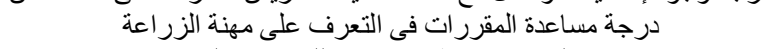 & \\
\hline *. Trt & درجة الرضا عن نظام الإختيار للمقررات الدر اسية & 9 \\
\hline$\because$ inv & درجة الرضا عن مو اعيد در اسة المقررات الدراسية & 1. \\
\hline $.1 r$. & درجة اختلاف توقع الطلاب للكلية قبل وبعد الإلتحاق بها & 11 \\
\hline
\end{tabular}

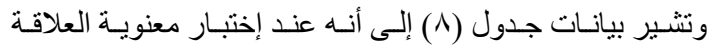

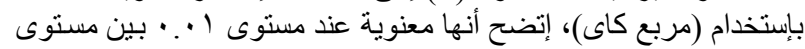

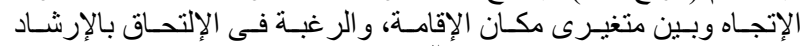

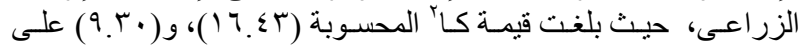

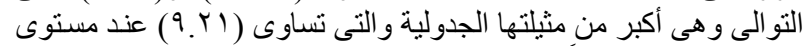

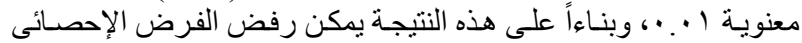

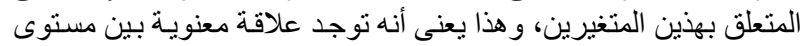

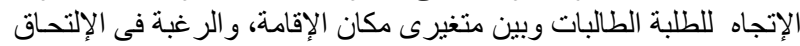
بالإرشاد الزراعى الطلى كما تشير بيانات نفس الجدول إلى أنه عند إختبار معنويـة العلاقة إنها

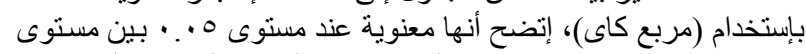

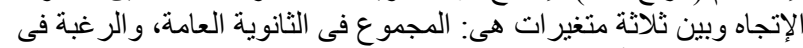

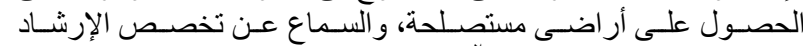

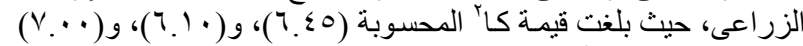

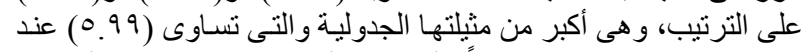

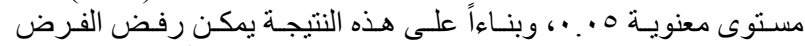

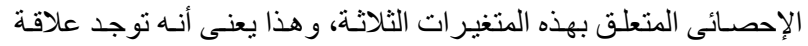

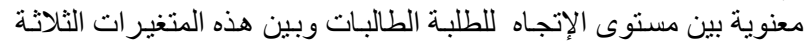

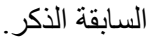
كذلك يوضـح نفس الجدول قيم مربع كاى بين مستوى الإتجـاه

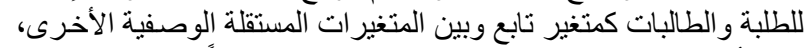

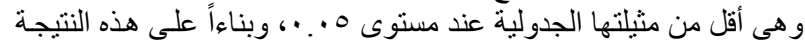

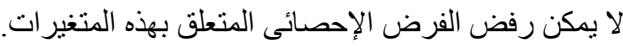

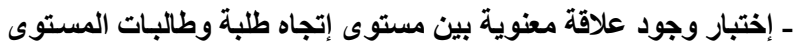

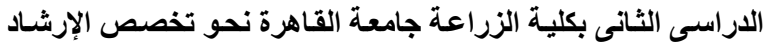

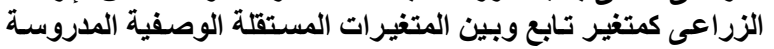

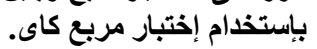

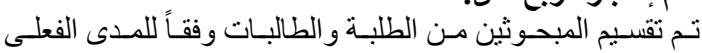

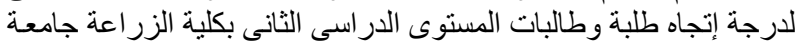

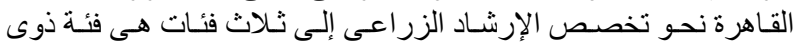

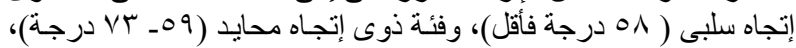

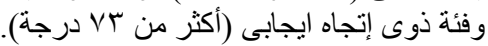

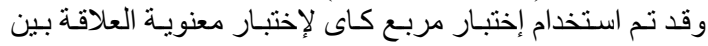

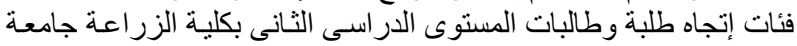

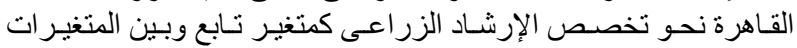

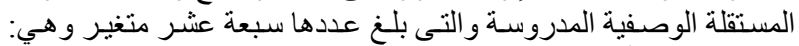

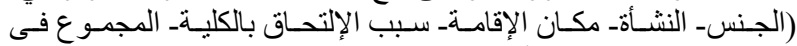

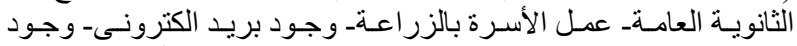

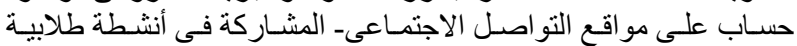

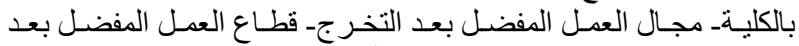

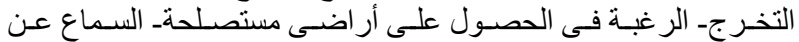

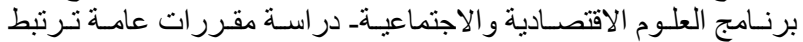

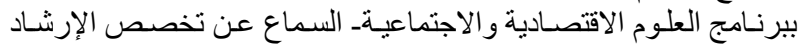

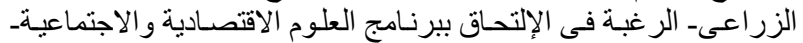

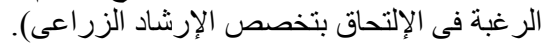

جدول (^) قيم مربع كاى المحسوبة للعلاقة بين مستوى إتجـاه الطلبة والطالبـات نحو تخصص الإرشـاد الزراعى وبين المتغيرات المستقلة الوصفية

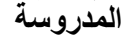
المتغيرات المستقلة الوصفية قيمة مربع كاى

1.11 $* * i \frac{1}{4} \leqslant$

$r .$.

*4. $\leqslant 0$

.79

$.7 \varepsilon$

.$r 0$

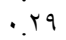

$\because r r$

$1 . \mathrm{YN}$

*7. 1 .

$1 . \wedge \varepsilon$

1.11

$* \dot{v} . \cdots$

$0, T \varepsilon$

**q. r.

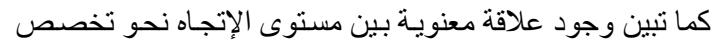

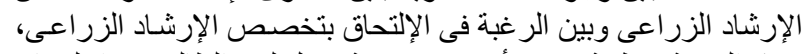

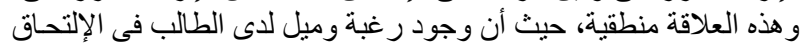

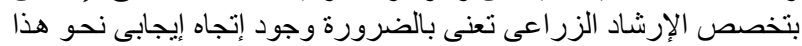

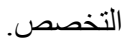

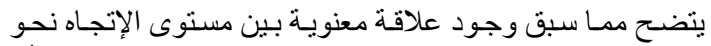

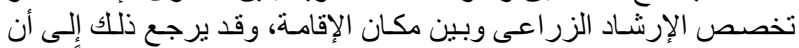

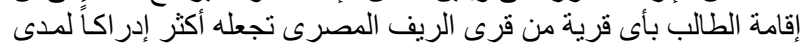

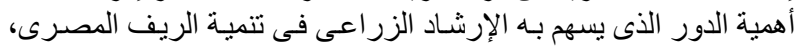

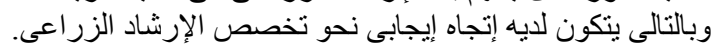




\section{J. Agric. Econom. and Social Sci., Mansoura Univ., Vol.7 (3), March ,2016}

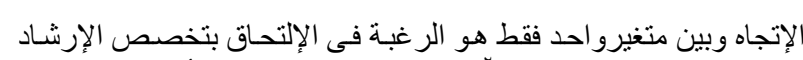

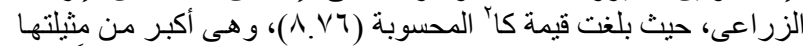

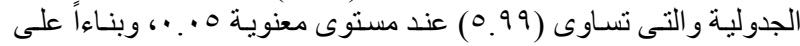

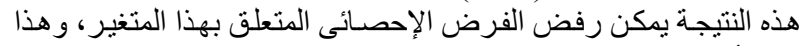

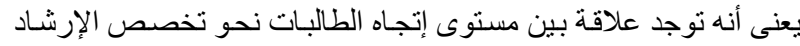

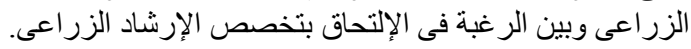

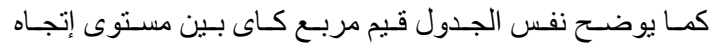

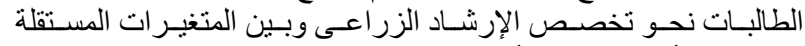

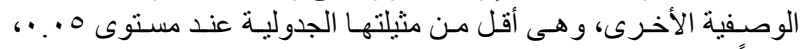

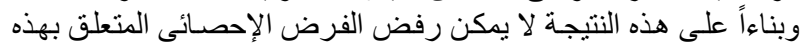

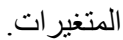

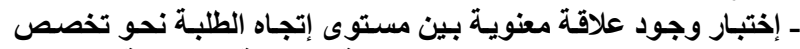

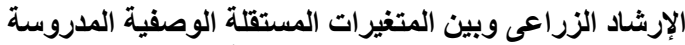

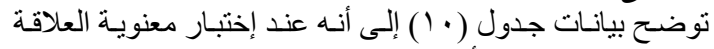

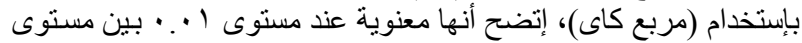

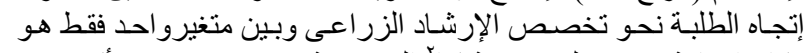

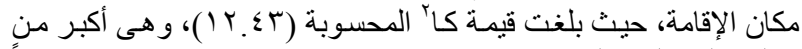

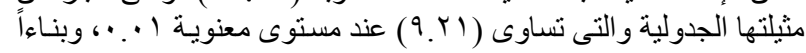

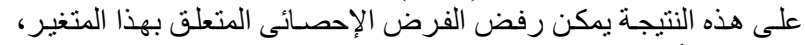

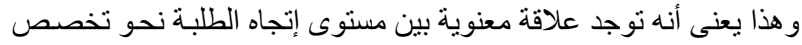
الإرشاد الزي اعى وبين مكان الإقامة.

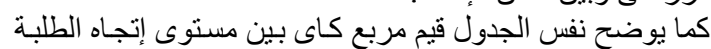

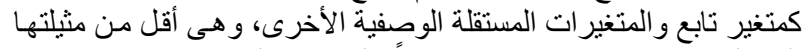

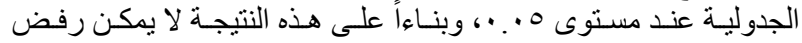

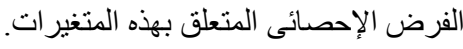

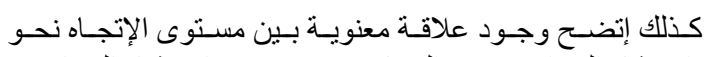

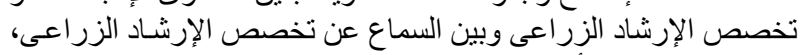

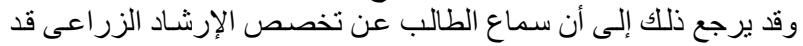

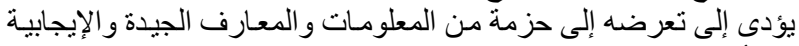

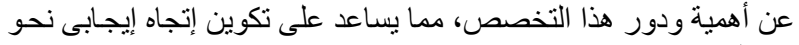
هذا التخصص. أهمية ودور.

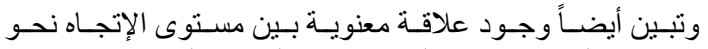

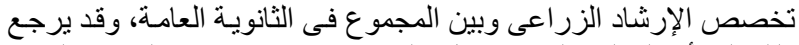

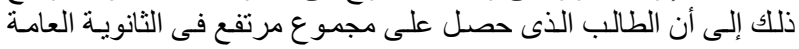

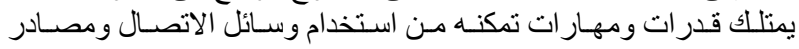

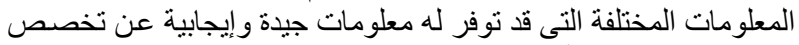

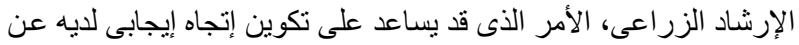
هذا التخصص.

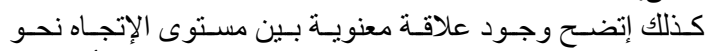

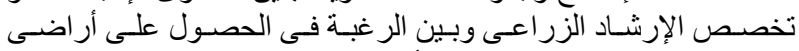

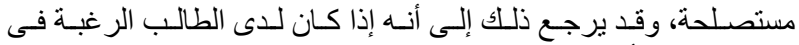

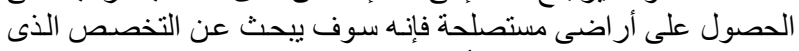

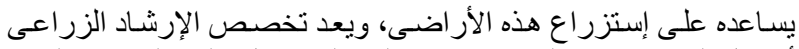

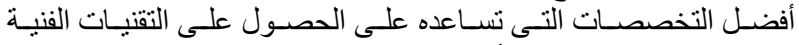

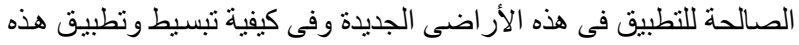

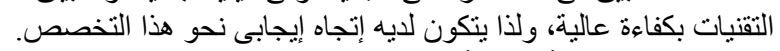

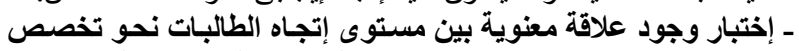

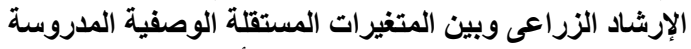

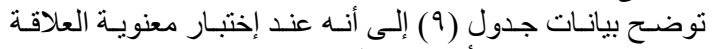

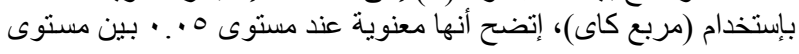

جدول (9) قيم مربع كاى المحسوبة للعلاقة بين مستوى إتجاه الطالبات نحو تخصص الإرشاد الزراعى وبين المتغيرات المستقلة الوصفية المدروسة

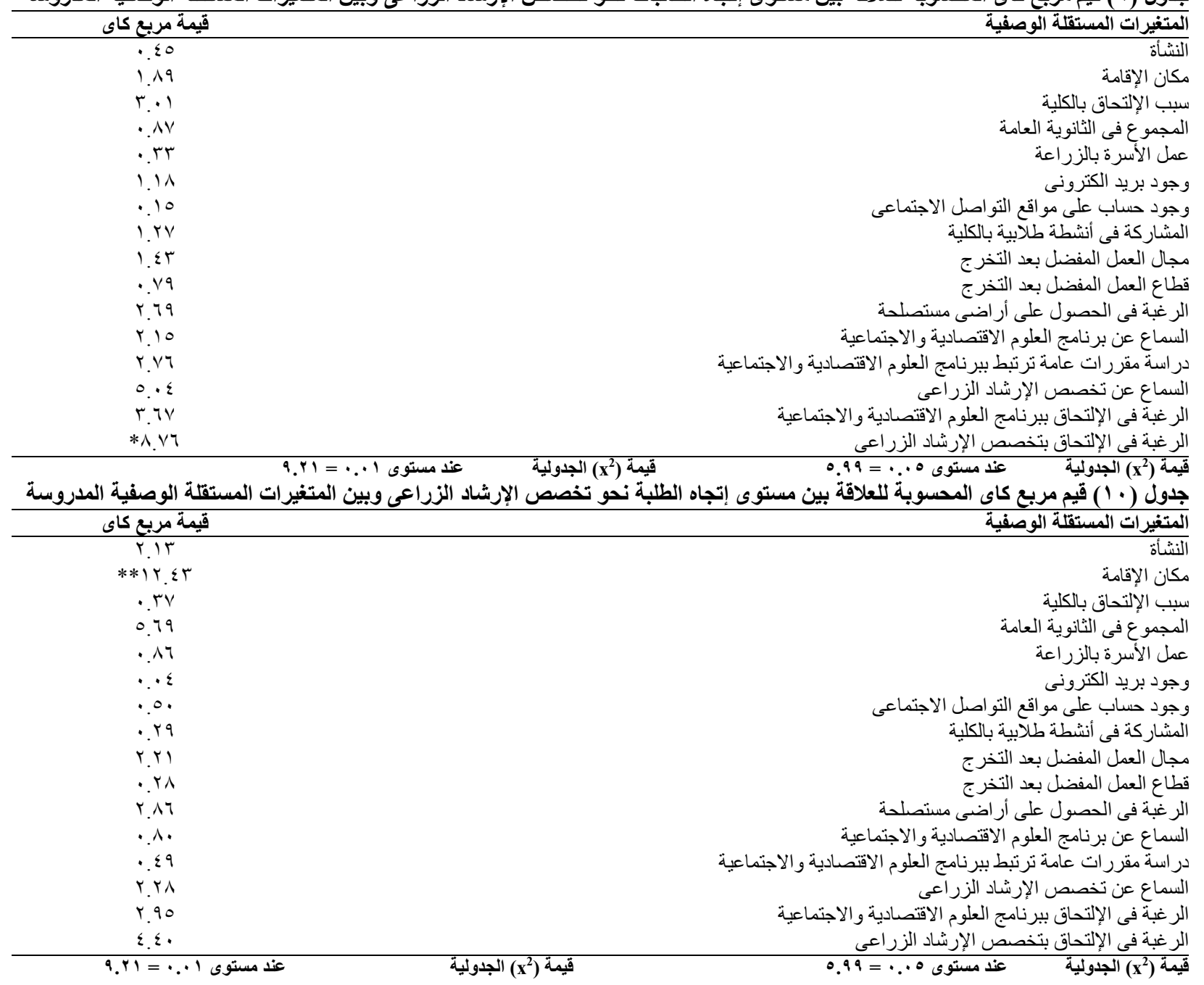




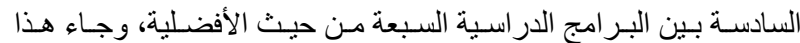

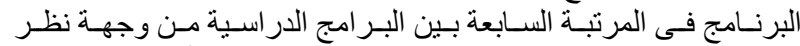

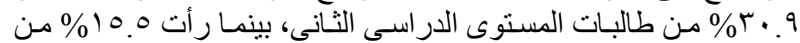
الطالبات أن هذا البرنامج يقع فى البـ المرنبة الخامسة.

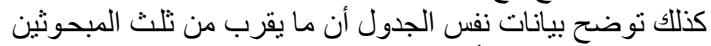

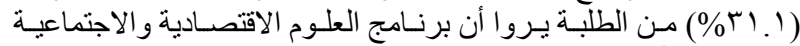

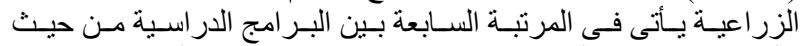

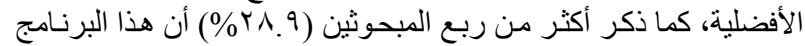

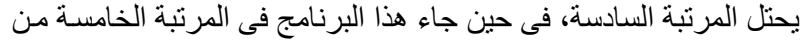

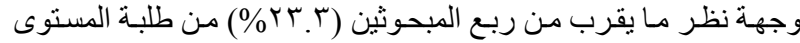

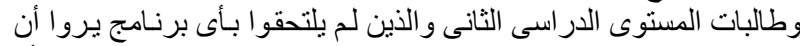

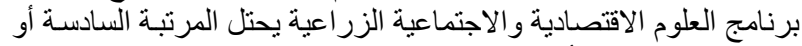

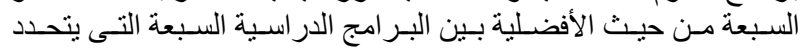

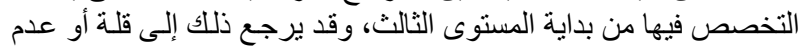

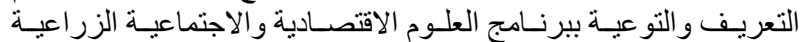

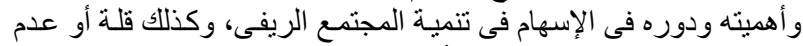

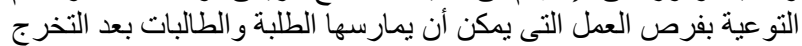
من هذا البرنامج.

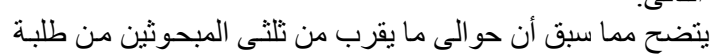

ع ـ درجة أفضلية برنـامج العلوم الاقتصادية والاجتماعية الزراعية بين

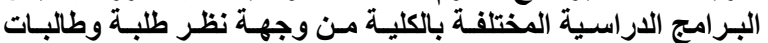

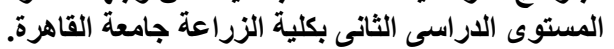

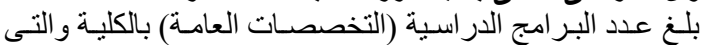

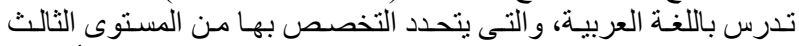

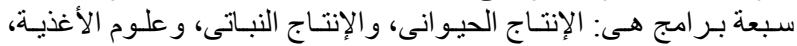

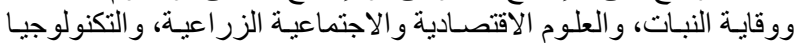

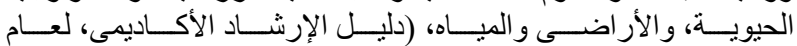

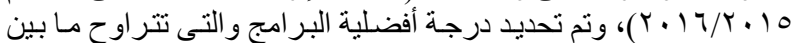

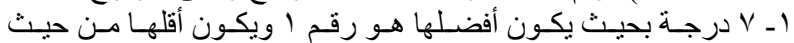

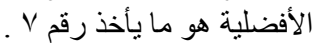

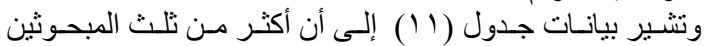

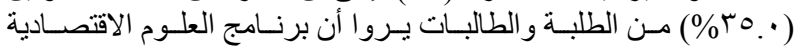

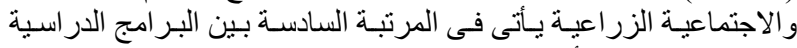

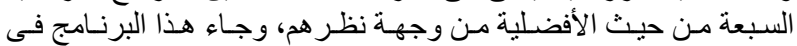

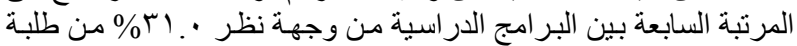

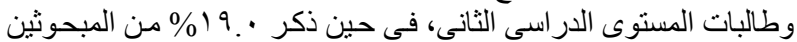
أن هذا البرنامج يقع فى المرتبة النئة الخامسة.

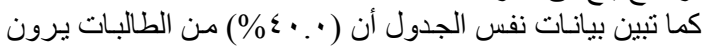

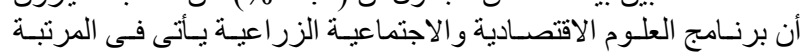

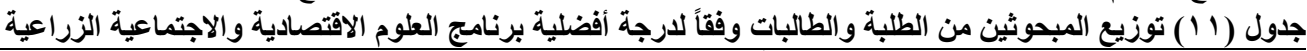

\begin{tabular}{|c|c|c|c|c|c|c|}
\hline \multicolumn{2}{|c|}{ الطلبة } & \multicolumn{2}{|c|}{ الطالبات } & \multicolumn{2}{|c|}{ الطنبة و الطالبات } & \multirow{2}{*}{ رتيب الأفضلية } \\
\hline$\%$ & عدد & $\%$ & عدد ( ع & $\%$ & عدد & \\
\hline 1.1 & 1 & --- & --- & .0 & 1 & 1 \\
\hline r.r & $r$ & .9 & 1 & $r_{.}$. & $\varepsilon$ & r \\
\hline r.r & r & $r .7$ & $\varepsilon$ & $r$. & 7 & r \\
\hline $1 \because$. & 9 & 9.1 & 1. & 9.0 & 19 & $\varepsilon$ \\
\hline r.r & rI & 10.0 & IV & 19. & rᄉ & 。 \\
\hline rA. 9 & r & $\varepsilon \cdot$. & $\varepsilon \varepsilon$ & ro. & v. & 7 \\
\hline T.. & rA & $r \cdot .9$ & $\Gamma \varepsilon$ & r.. & $\pi$ & v \\
\hline $1 \ldots$ & 9. & $1 \ldots$ & 11. & $1 \ldots$ & r.. & الإجمالى \\
\hline
\end{tabular}

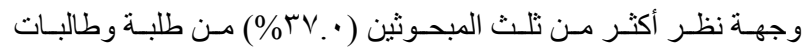

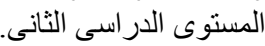

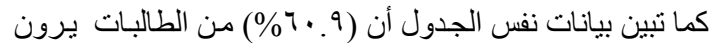

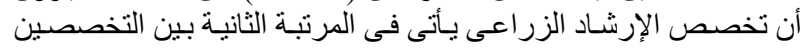

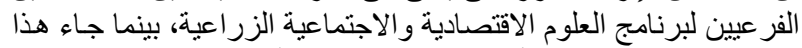

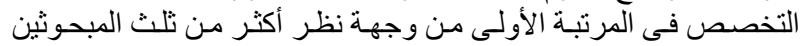

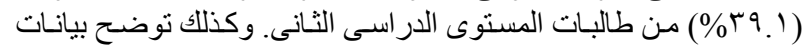

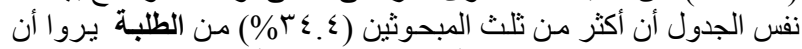

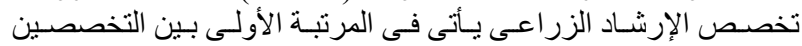

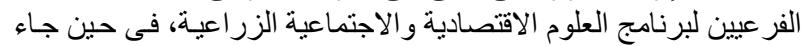

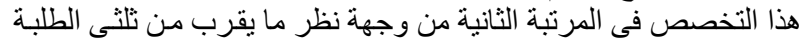

$(\% 70.7)$

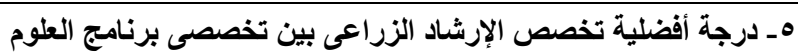

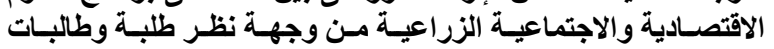

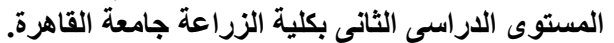

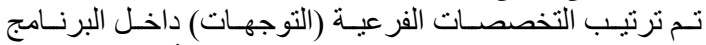

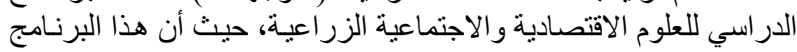

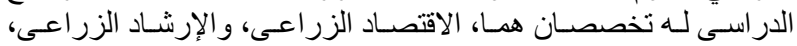

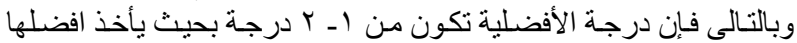

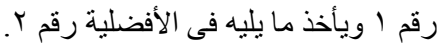

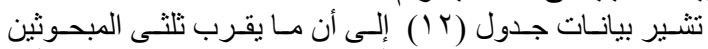

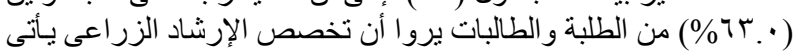

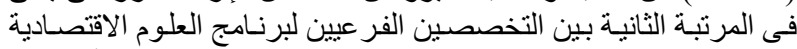

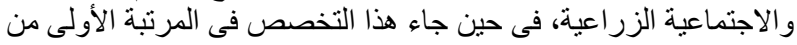

جدول (r I ) توزيع المبحوثين من الطلبة والطالبات وفقاً لارجة أفضلية تخصص الإرشاد الزراعى

\begin{tabular}{|c|c|c|c|c|c|c|}
\hline \multicolumn{2}{|c|}{ الطلبة } & \multicolumn{2}{|c|}{ الطالبات } & \multicolumn{2}{|c|}{ الطلبة والطالبات } & \multirow{2}{*}{ ترتيب الأفضلية } \\
\hline$\%$ & عدد & $\%$ & عدد & $\%$ & عدد & \\
\hline$r \varepsilon . \varepsilon$ & rT & r9.1 & $\varepsilon \pi$ & $r v$. & $V \varepsilon$ & 1 \\
\hline 70.7 & 09 & 7.9 & TV & ז. & $1 \times 4$ & r \\
\hline $1 \ldots$ & 9. & $1 \ldots$ & 11. & $1 \ldots$ & r.. & الاجمالى \\
\hline
\end{tabular}

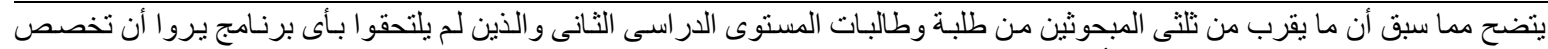

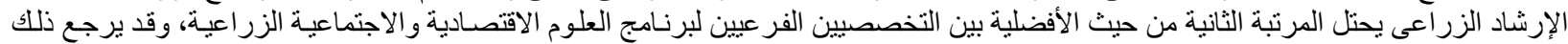

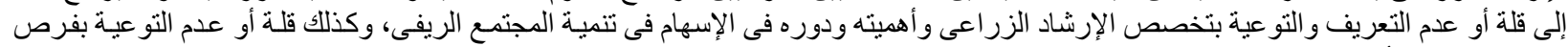

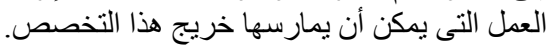

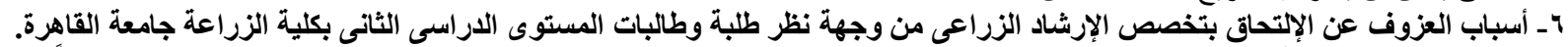

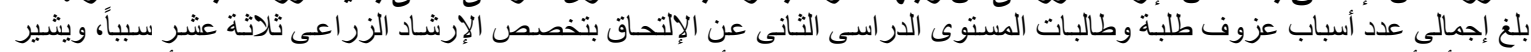

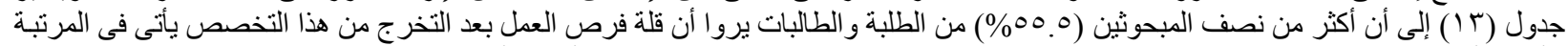

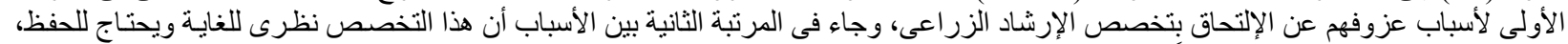

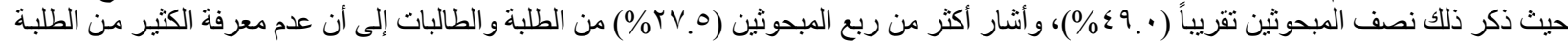

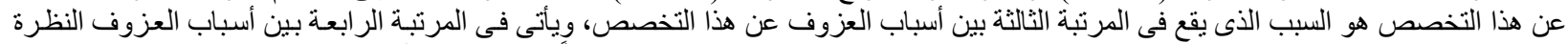

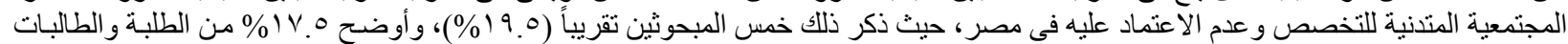

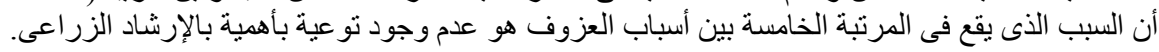




\begin{tabular}{|c|c|c|}
\hline$\%$ & عدد & أسباب عزوف الطلبة وطالبات \\
\hline 00.0 & 111 & قلة فرص العمل بعد التخرج من هذا التخصص \\
\hline$\leqslant 9$. & 91 & التخصص نظرى ويحتاج للحفظ \\
\hline$r V_{0} 0$ & 00 & عدم معرفة الكثير من الطلبة عن هذا التخصص \\
\hline 19.0 & rq & النظرة المجتمعية المتندية للتخصص و عدم الاعتماد علبه في مصر \\
\hline $1 V .0$ & ro & عدم وجود نو عية بأهمية بالارشاد الزر اعى \\
\hline 1.0 & Y) & الرغبة وتفضيل التخصصات العملية الأخرى \\
\hline $1 \cdot$. & r. & عدم الاهتمام بالمرشد الزر اعى وتقديره مادياً ومعنوياً \\
\hline 9.0 & 19 & عدم الرغبة و عدم الميل الشخصى تجاه التخصص \\
\hline 1.0 & IV & وجود صعوبة في التعامل مع أعضاء هيئة التنريس بهذا التخصص \\
\hline$v_{.} \cdot$ & $1 \varepsilon$ & مجال و أماكن العمل غير ملآئمة وصعبة لانها فى القرى \\
\hline 7.0 & ir & صعوبة عمل البنات بعد تخرجهم من هذا التخصص \\
\hline 7. & ir & التخصص مغلق منذ فترة وبه عدد قليل من الدارسين \\
\hline$\varepsilon$ & $\wedge$ & التكنولوجيا تسهل حصول الزر اع على المعلومات وتقلل من أهمية الإرشاد \\
\hline
\end{tabular}

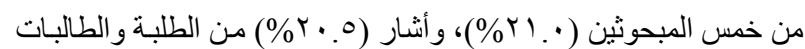

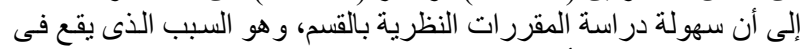

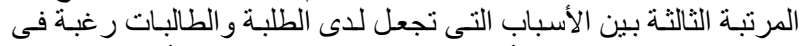

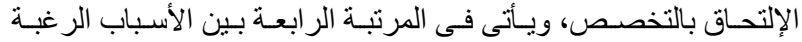

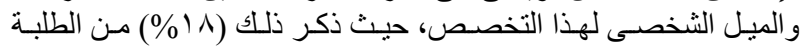

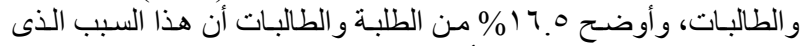

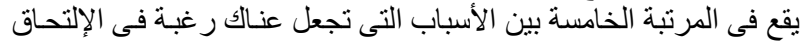

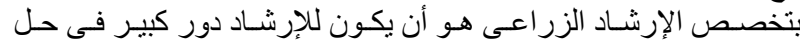

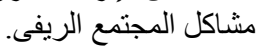

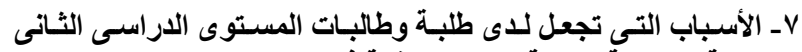

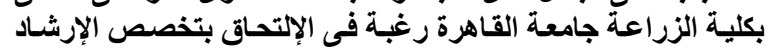
الزراعى.

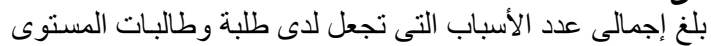

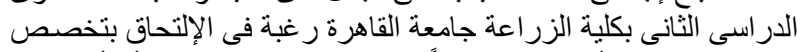

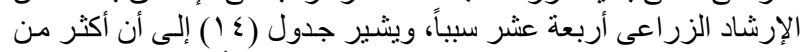

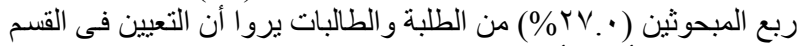

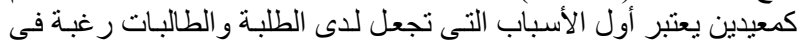

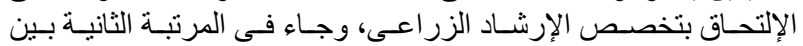
الأسباب تفضيل الأقسام النظرية على الأقسام العملية، حيث ذكر ذللك أكثر

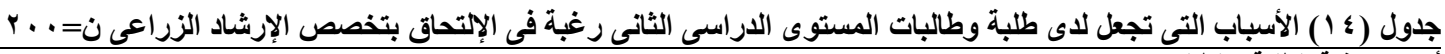

\begin{tabular}{|c|c|c|}
\hline$\%$ & عدد & أسباب رغبة الطلبة والطالبات \\
\hline$T V_{.} \cdot$ & $0 \leqslant$ & التعيين فى القسم كمعيدين \\
\hline r.. & $\leqslant r$ & تفضيل الأقسام النظرية على الأقسام العطلية \\
\hline$r \cdot .0$ & « & سهولة در اسة المقرر ات النظرية بالقسم \\
\hline 11. & r & الرغبة و الميل الشخصى لهذا التخصص \\
\hline 17.0 & rr & أن يكون للإرشاد دور كبير فى حل مشاكل المجتمع الريفى \\
\hline $1 \leqslant 0$ & rq & حب التو اصل و المشاركة الاجتماعية مع المز ارعين \\
\hline 11.0 & rt & سهولة الحصول على التقدير \\
\hline 11. & rt & الرغبة فى العمل كمرشد \\
\hline 9. & 11 & أن يكون لخريج التخصص فرصة التعيين فى وظيفة حكومية \\
\hline i. & 17 & أن يكون من أسرة لديها أرض زر اعية أو ذو نشأة ريفية \\
\hline 0. & 1. & التخصص متاح لكل الطلبة \\
\hline$\leqslant 0$ & 9 & قلة عدد الدر اسين بالتخصص \\
\hline$r$. & 7 & كفاءة اعضاء هيئة التدريس بالقسم وتشجعيهم الإلتحاق به \\
\hline r.o & 。 & التعيين كباحث في مركز البحوث الزر اعية \\
\hline
\end{tabular}

النهوض بجميع المجالات الزر اعية وبالتالى الإسهام فى تنمية المجتمع

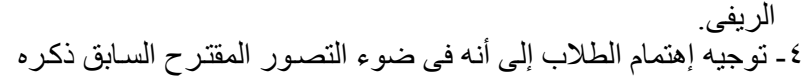

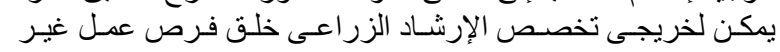

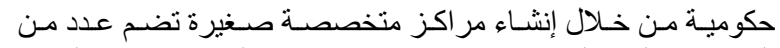

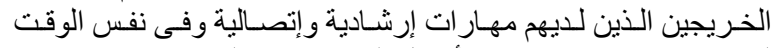

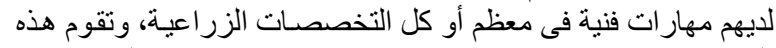

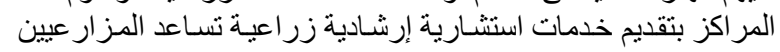

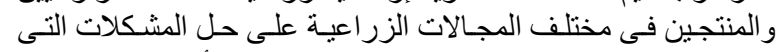

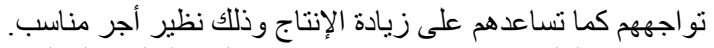

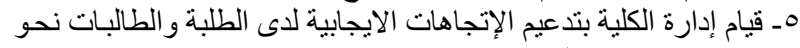

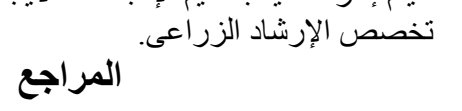

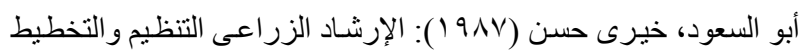

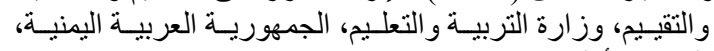
الطبعة الأولى.

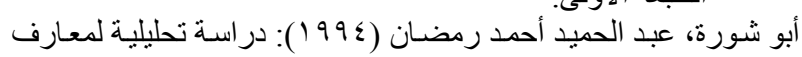

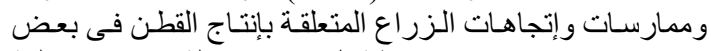

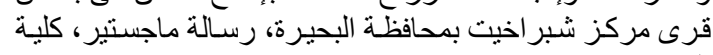
الزر اعة، جامعة الاسكندرية.

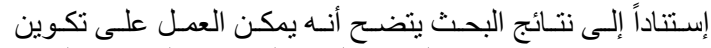

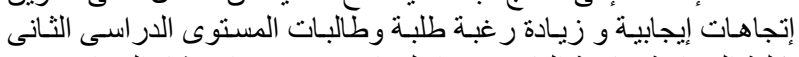

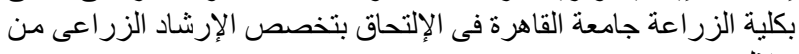

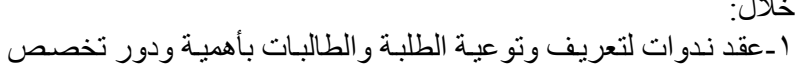

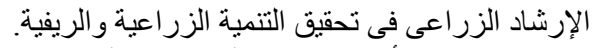

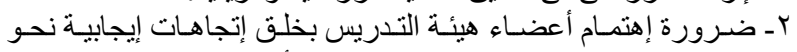

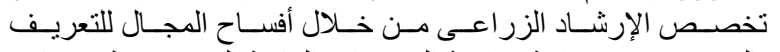

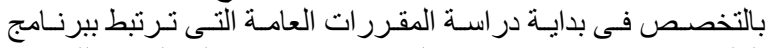

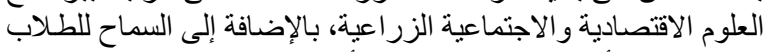

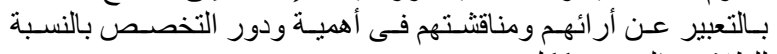

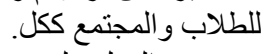

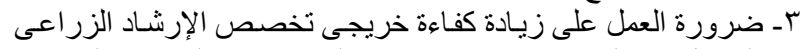

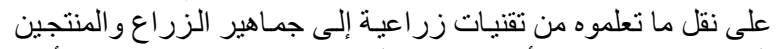

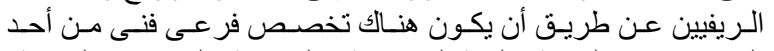

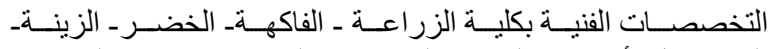

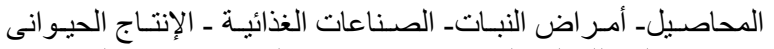

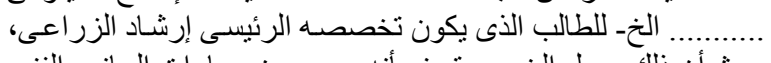

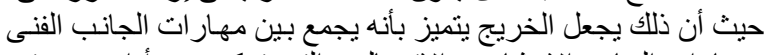

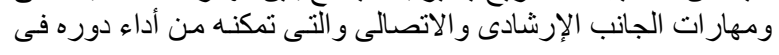




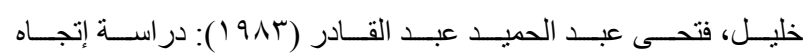

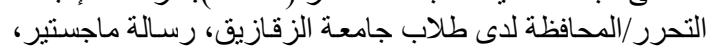

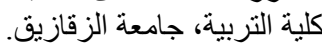

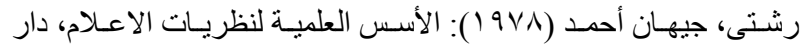

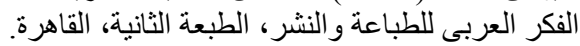

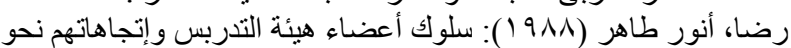

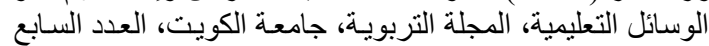

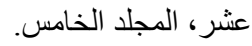

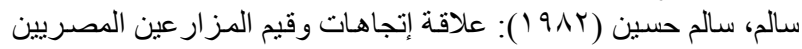

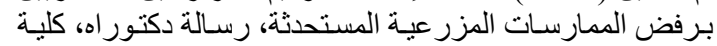

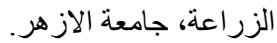

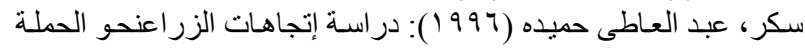

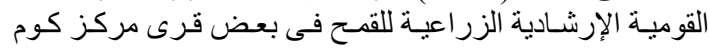

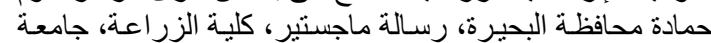

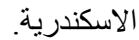

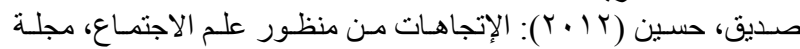

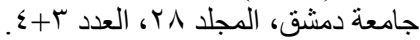

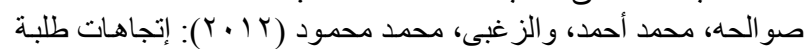

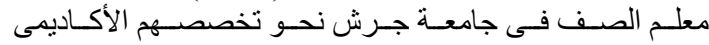

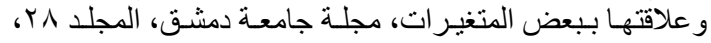

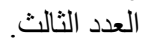
عبد الرحبم، طلعت حسن (1919 ()): علم النفس الاجتمـاعى المعاصر ، دار الثقافة، القاهرة، الطبعة الثانية.

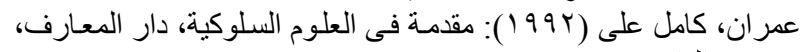

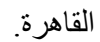

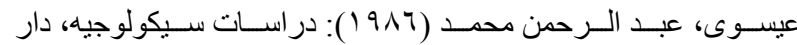

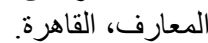

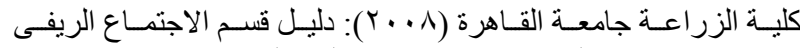

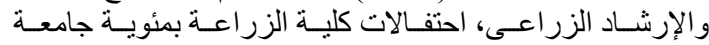

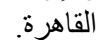

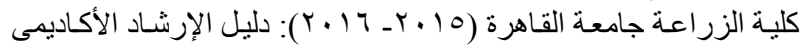

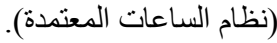

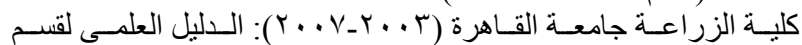

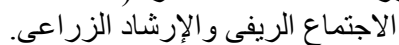

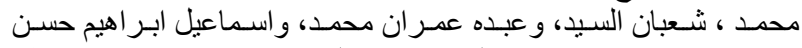

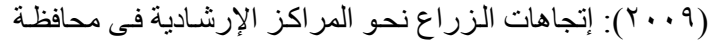

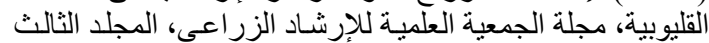

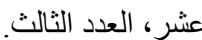

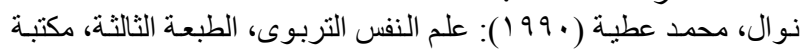

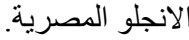

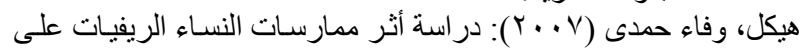

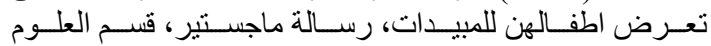

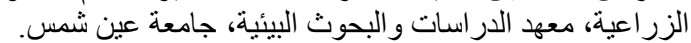

Brock, T \& Green, M. (2005): Psychological insights and Perspectives, Thousand Oaks: CA: Sage Publications

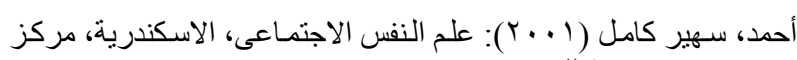

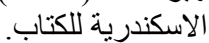

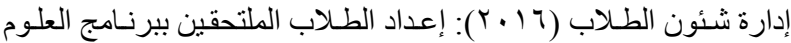

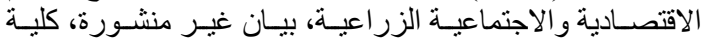

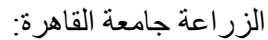

السيد، عبد الحليم محمود (9V9 ( ) ): علم النفس الاجتمـاعى و الاعلام، دار النقافة للطباعة و النشر ، القاهرة

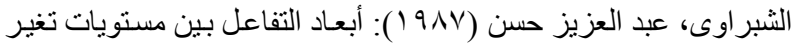

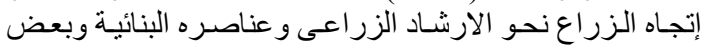

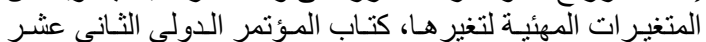

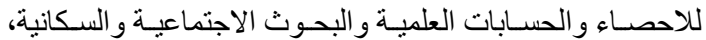
القاهرة.

الطنوبى، محمد عمر (991 (191): معجم المصطلحات الإرشـادية الزر اعية،

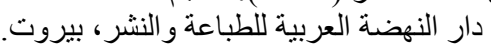

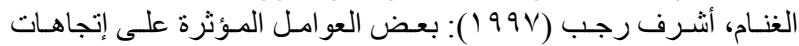

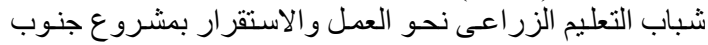

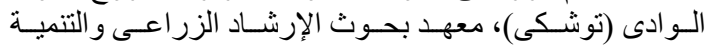

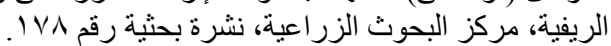

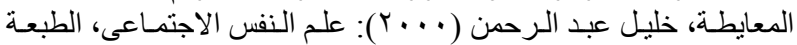

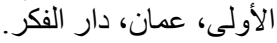

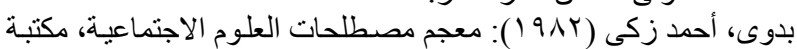

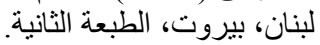

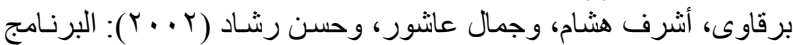

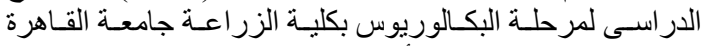

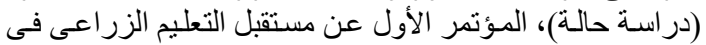

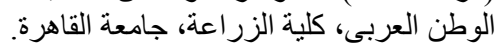

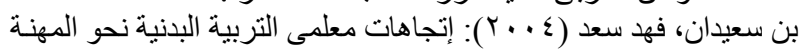

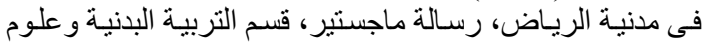

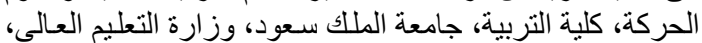

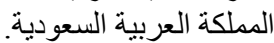

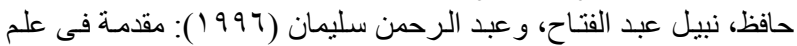

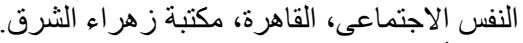

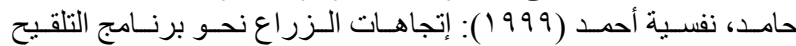

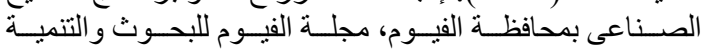

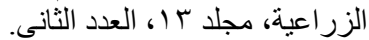

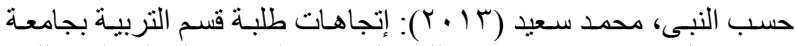

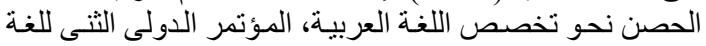

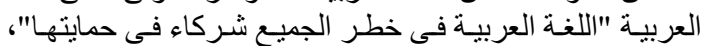

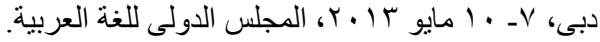

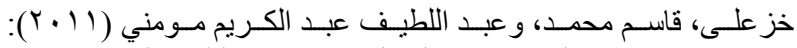

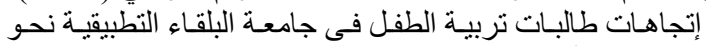

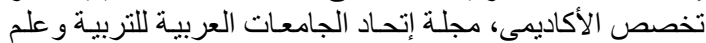
النفس، المجلد التاسع، العدد الأول.

Shringley, R. (1983): The Attiudude concept and Science Teaching, Science Education, 67 (4), pp 425- 442

Bohner \& Wanke (2002): Attitudes and Attitudes Change, Hove, UK, Psychology Press. 
ATTITUDES OF MALE AND FEMALE STUDENTS OF SECOND STUDIOUS LEVEL IN FACULTY OF AGRICULTURE OF CAIRO UNIVERSITY TOWARDS AGRICULTURAL EXTENSION SPECIALIZATION

Sahar A. Hikel

Faculty of Agriculture- Cairo University

\begin{abstract}
The Main objectives of this research were to determine: the sources of information of male and female students of second studious level in Agriculture Faculty of Cairo University about their college and its specializations, the degree of attitude of the students towards Agricultural Extension Specialization (AES), the relationship between the degree of attitude of the students towards (AES) and the set of independent variables, the degree of preference of Agricultural Social and Economic Sciences Program (ASESP) between other programs from viewpoint of students, the degree of preference of (AES) between two specializations of (ASESP) from viewpoint of students, reasons of reluctance of the students about joining with (AES), and reasons of the students desire to joining with (AES).

The total population of respondents of all the male and female students of second studious level in Agriculture Faculty of Cairo University who did not specialize yet was 270 students, and the number of respondents in the sample was 200 , this sample repersent $74 \%$ of the total population.

Data were collected by interviews with respondents using a questionnaire designed and pre-tested for the purposes of the research. Percentages, Range, Frequencies, Arithmetic mean, Standard deviation, Chi square test, Pearson's correlation coefficient were used for data presentation and analysis.

The important results of the research could be summarized as follows:

- $63 \%$ of the students mention that the other students and friends were the source of their information about college and its specializations.

$-31.5 \%$ of the students have a negative attitude towards (AES)

- There are significant relationship between the degree of the attitude of the students with the degree of courses assistance in identifying the profession of agriculture, the appropriate degree of the examinations system, the degree of satisfaction about the system of courses selection, the degree of the differance of students prediction for the College before and after the joining, place of residence, and the total degree in secondary school.

- 35\% of the students mentioned that (ASESP) comes in sixth place in terms of preference between the seven programs that are taught in Arabic.

- $63 \%$ of the students mentioned that (AES) comes in second place between two specializations of (ASESP).

- 55.5\% of the students mentioned that the lack of employment opportunities after graduation was the most important reasons for reluctance about joining with (AES).

- $27 \%$ of the students mentioned that the appointment to be demonstrators in departement of Agricultural Extension was the most important reasons for joining with (AES)
\end{abstract}

